\title{
RELATIVE SEA-LEVEL VARIATIONS REVEALED BY TIDE-GAUGE RECORDS OF LONG DURATION \\ by
}

ANTHONY JAMES WiTHNELL

B.Sc. Geology, Indiana University

(1981)

submitted to the

Massachusetts Institute of Technology/Woods Hole Oceanographic Institution

Joint Program in Oceanography and Oceanographic Engineering

in partial fulfillment of the requirements

for the degree of

Master of Science

at the

Massachusetts Institute of Technology

and the

Woods Hole Oceanographic Institution

June 1990

\begin{tabular}{c}
\hline $\begin{array}{c}\text { MARINE } \\
\text { BIOLOGICAL } \\
\text { LGOORATORY }\end{array}$ \\
\hline LIBRARY \\
\hline $\begin{array}{c}\text { WOOOS HOLE, MASS. } \\
\text { W. H. O. I. }\end{array}$ \\
\hline
\end{tabular}

(C) Anthony J. Withnell 1990

The author hereby grants to M.I.T. and WHOI permission to reproduce and distribute copies of this thesis document in whole or in part.

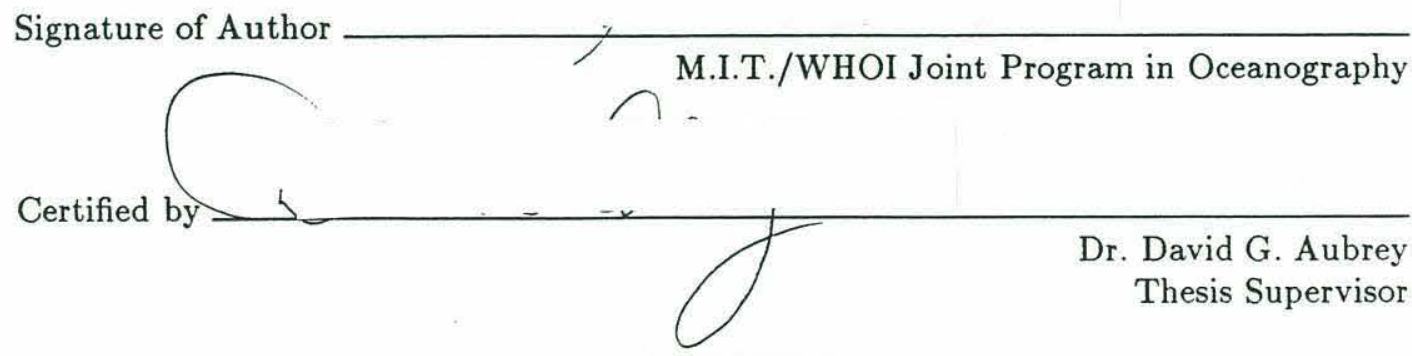

Accepted by

Dr. George P. Lohmann, Chairman

Joint Committee for Marine Geology \& Geophysics

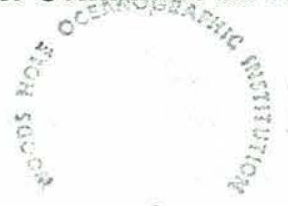




\title{
RELATIVE SEA-LEVEL VARIATIONS REVEALED BY TIDE-GAUGE RECORDS OF LONG DURATION
}

\author{
by \\ ANTHONY James WithnelL
}

submitted to the Massachusetts Institute of Technology/Woods Hole Oceanographic Institution Joint Program in Oceanography and Oceanographic Engineering on February 23, 1990

in partial fulfillment of the requirements for the degree of

Master of Science in Marine Geology \& Geophysics

\begin{abstract}
Trends in mean relative sea-level and patterns of occurrence of extreme sea levels are analyzed separately in the two parts of this thesis.

In Part 1, twenty-eight of the world's longest tide-gauge records are examined for clues to the uncertain balance among factors contributing to relative sea-level (RSL) fluctuations. Obtaining these clues requires a description of the data in terms of component functions, whether chosen for their special properties (regression analysis) or empirically determined (EOF analysis). Part 1 describes a regression model that allows for gradual changes of the RSL trend and for sudden changes in the level to which tide-gauge measurements are referred (gauge zero); also described is an EOF analysis procedure that offers certain advantages in the handling of missing observations. Although the rate of RSL rise exhibits significant gradual change over 60- to 120-year analysis intervals at many stations, no support is found for the idea of a gradual global acceleration of RSL rise. Results that seem to show RSL rise accelerating globally over the last century can be attributed instead to the changing geographical distribution of tide-gauge observations. Regional and local controls, which include vertical crustal movements and changes due to oceanographic or meteorological effects, must be responsible for the accelerations documented at many stations, and are dominant in controlling shorter-term departures from the RSL trend too. Preliminary results of EOF analysis reveal regionally coherent fluctuations of annual mean RSL in the Baltic Sea with r.m.s. amplitudes as large as $70 \mathrm{~mm}$. Globally coherent fluctuations have smaller r.m.s. amplitudes: a tentative upper limit is $20 \mathrm{~mm}$.

In Part 2, 40 years of hourly sea-level records from two stations on the midAtlantic coast of the U.S. are used in a compilation of monthly 'surge'-level exceedance counts. 'Surge' level is defined as observed sea level minus predicted tide level. The results are compared with previously published storm counts, and the annual cycle of 'surge'-level exceedance frequency is found to lead that of storm frequency by nearly two months. It is recommended that further work aimed at modelling 'surge'-level exceedances should include: (i) recognition that the tide record includes meteorological/oceanographic as well as astronomical components, especially at the frequency of the solar annual tide, and (ii) quantification of the relative importance of tide and surge in the timing of extreme sea-level occurrences at different times and places.
\end{abstract}

Thesis Supervisor: Dr. David G. Aubrey

Title: Associate Scientist and Director, Coastal Research Center Woods Hole Oceanographic Institution 


\section{Contents}

Introduction . . . . . . . . . . . . . . . . . . . . 6

$\begin{array}{lr}\text { Part 1. Mean relative sea level trends } & 8\end{array}$

Introduction to Part $1 \ldots \ldots \ldots \ldots \ldots \ldots$

Previous results . . . . . . . . . . . . . . . . . . . . . . . . . 9

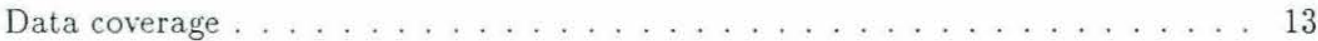

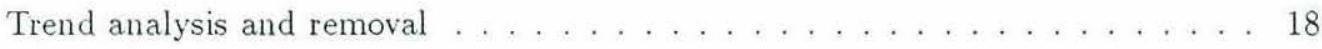

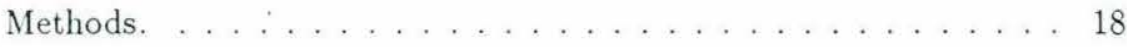

Results. ........................ 24

Empirical orthogonal function (EOF) analysis . . . . . . . . . . . . . . 31

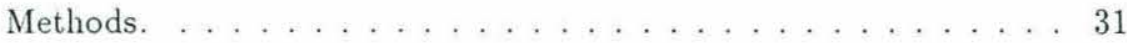

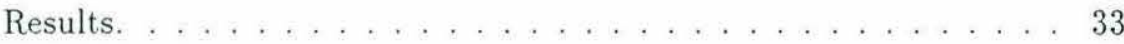

Interpretation . . . . . . . . . . . . . . . . . . . 35

Status of work and future directions . . . . . . . . . . . . . . . . 39

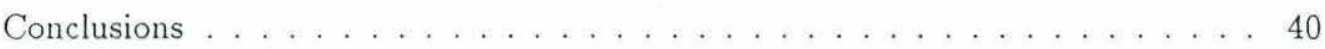

Appendix 1. Numerical example . . . . . . . . . . . . . . . . . 42

Appendix 2. Remarks on EOF analysis of incomplete data sets . . . . . . . 45

Part 2. Occurrence of extreme sea levels $\quad 53$

Data coverage . . . . . . . . . . . . . . . . . . . 53

Compilation of monthly exceedance counts . . . . . . . . . . . . 56

Comparison of exceedance counts and storm counts . . . . . . . . . . . . . 59

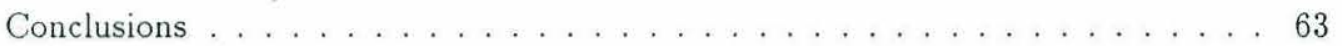

$\begin{array}{ll}\text { References } & 65\end{array}$ 


\section{List of Figures}

1 The 28 tide-gauge stations included in the study, and the years of data utilized. . . . . . . . . . . . . . . . . . . . 16

2 Locations of the 28 tide-gauge stations listed in figure $1 \ldots \ldots . . . . .17$

3 Sample plots of annual mean sea-level elevation . . . . . . . . . . . . . 19

4 Residual variance $s^{2}$ after quadratic trend removal, and linear trend $b$ from a straight-line fit. . . . . . . . . . . . . . . . . . . 25

5 Derivatives of quadratic regression curves. . . . . . . . . . . . . 26

5 Continued. . . . . . . . . . . . . . . . . . . 27

6 Variation of global mean sea level derived by averaging data from the stations reporting for each year. . . . . . . . . . . . . . . . . . 29

7 Number of consecutive observations required to render a quadratic trend statistically significant . . . . . . . . . . . . . . . . 30

8 Results of EOF analysis . . . . . . . . . . . . . . . . . . 34

9 Locations of 5 sea-level stations on the U.S. East Coast. . . . . . . . . . . 54

10 Four months of hourly tide-gauge data from Atlantic City . . . . . . . . . 55

11 Tide and 'surge' components of a tide-gauge record. . . . . . . . . . . . 58

12 Averaged monthly exceedance counts and storm counts . . . . . . . . . . 61

\section{List of Tables}

1 Global averages of the rate of sea-level rise, and estimates of the eustatic contribution. . . . . . . . . . . . . . . . 10

2 Tide-gauge stations with records of long duration qualifying for inclusion in the study. . . . . . . . . . . . . . . . . . . 14

3 Analysis of variance: matrix computational formulae for a quadratic regression 23

4 Contributions to the rate of RSL rise. . . . . . . . . . . . . . 38

5 Analysis of variance: numerical example. . . . . . . . . . . . . . . 43

6 Data coverage in study of sea-level extremes. . . . . . . . . . . . . . . 53

7 Data removed . . . . . . . . . . . . . . . . . 56

8 Thresholds and average exceedance counts . . . . . . . . . . . . . . 59

9 Averaged monthly exceedance counts . . . . . . . . . . . . . . . . 60 
Acknowledgments. Data were provided by the Permanent Service for Mean Sea Level, Birkenhead, England; and the National Ocean Service, Rockville, Maryland. Mean sea-level data for Bombay have been supplied by No. 68 (Tidal) Party, Geodetic \& Research Branch, Survey of India, with the permission of the Surveyor General of India. The author was supported by the Education Office of the Woods Hole Oceanographic Institution (WHOI). This work is the result of research sponsored by the National Oceanic and Atmospheric Administration Sea Grant College Program Office, Dept. of Commerce, under Grants No. NA83-AA-D-0049 and No. NA86-AAD-SG090, WHOI Sea Grant Project No. R/O-4. Computations were funded in part by the National Science Foundation under Grant No. OCE-8501174, and by the WHOI Coastal Research Center. The U.S. Government is authorized to produce and distribute reprints for governmental purposes notwithstanding any copyright notation that may appear hereon.

I am deeply indebted to David G. Aubrey of WHOI for advice, encouragement, and critical reviews of drafts of this paper. Peter Schweitzer and Elazar Uchupi of WHOI participated in helpful discussions. Valuable assistance was received from Sue Volkmann, Warren Sass, and other staff of WHOI's Information Processing and Communications Laboratory. Special thanks are due to my parents for their unwavering support and understanding over the years. 


\section{RELATIVE SEA-LEVEL VARIATIONS REVEALED BY TIDE-GAUGE RECORDS OF LONG DURATION}

\section{Introduction}

This work is divided into two parts, dealing respectively with annually averaged sea levels and with the occurrence of extreme sea levels.

The first part addresses questions concerning the existence of "global" trends in mean sea level relative to land level over the last century or so. It examines the character and relationship of trends evident in tide-gauge records of long duration from widely separated locations. The statistical methods employed in analyzing such records are scrutinized, and the results emphasize the importance of regional and local deviations from supposed "global" trends. No evidence is found for the idea that there has been a global acceleration in the rates of mean relative sea level rise over the time span for which records are available. Considerable efforts in data collection and careful analysis will be required if the global, regional, and local components of future acceleration, widely predicted as a consequence of atmospheric warming, are to be separated.

Changes in mean sea level are naturally accompanied by changing patterns of extreme sea level occurrences. Although the mean sea level may more directly reveal long-term trends in mean global temperature, it is the extreme events whose impact is of greater concern to coastal planners. Understanding the effect of long-term climatic changes on the pattern of extreme events requires taking into account not only mean sea level trends, but also storm climate which may also be subject to long-term variability. As the first stage in a project aimed at modelling extreme sea-level occurrences under changing climatic conditions, work is underway to formulate a regression model explaining the 'aperiodic' component of tidal records-that is, the observed sea level minus its periodic tidal component-in terms of meteorological variables (wind speed and barometric pressure). The progress of this effort and some preliminary results that have emerged from it are discussed in Part 2.

The study of extreme sea levels is based on 40 years (1948-1987) of hourly sea level observations from five stations on the east coast of the United States. With the separation of 'periodic' (tidal) and 'aperiodic' (meteorological and oceanographic) components accomplished, the dependence of the latter on meteorological variables remains to be in- 
vestigated. In the meantime, tables have been constructed for two stations (in Atlantic City and New York City) giving the number of times sea level exceeded a chosen threshold in each month. These tables of sea-level exceedances are directly comparable to tables of monthly storm counts for the mid-Atlantic coast prepared by Dolan et al. (1987). The results of this comparison are included in Part 2, and include the finding that the annually occurring rise and fall in the frequency of sea-level exceedances leads that of storm frequency by nearly two months. 


\section{Part 1. Mean relative sea level trends}

\section{Introduction to Part 1}

Cyclical changes in the elevation of the sea's surface, which are almost entirely accounted for by the gravitational theory of the tides, are measured at hundreds of stations around the globe on a regular basis. Many of these stations have records of long enough duration (between 20 and 200 years) to show also the effects of a gradual rise or fall of mean sea level relative to adjacent land masses. Independent confirmation of the existence of such changes exists, but the scientific evidence regarding their present rates resides to a large extent in the tide-gauge records. Part 1 of this paper is an analysis of the tide-gauge data collected since 1865 at twenty-eight stations.

On a longer time scale, relative sea-level (RSL) fluctuations during the Recent or Holocene epoch (the last 10 thousand years) have resulted in raised or submerged shorelines around the world, which under favorable conditions can be recognized and dated on the basis of paleo-ecological evidence, including peat deposits and oyster beds. Holocene shorelines can be found more than 100 metres above present-day sea level and as much as 50 metres below it (Gornitz \& Lebedeff, 1987), depending on the regional history of iceage glaciation and on the tectonic setting. Rates of vertical crustal movement are thought to have been between 10 and $100 \mathrm{~mm}$ per year ( 1 to 10 metres per century) in many areas during the most rapid phase of the glacial retreat (Nikonov, 1980). The last 6000 years have been characterized by much slower changes: in this interval, dated shoreline indicators agree with modern tide-gauge records in revealing rates of uplift or submergence to be less than $10 \mathrm{~mm}$ per year virtually everywhere (Gornitz \& Lebedeff, 1987).

Concern that sea levels may be starting to rise more rapidly again as a result of $\mathrm{CO}_{2}$ induced climatic changes has made RSL studies a focus of scientific and public attention recently. The importance of rising or falling sea levels to coastal communities and planners is certain. In the often intensively developed coastal zone, the economic consequences of sea-level change can be serious and the human impact remarkable. The steady emergence of new lands from the sea is a fact of life in Scandinavian countries, for instance, where hundreds of square kilometers of new real estate are reportedly divided among landowners every 50 years or so (Charlesworth, 1957). Elsewhere, land is being destroyed at comparable if not far greater rates: territory near the mouths of large rivers is especially hard hit, being prone to subsidence and increasingly subject to attack by the ocean because in many cases the fluvial sediment supply is being cut off by engineering projects upstream 
(Broadus et al., 1986). In some low-lying countries (the Netherlands, Bangladesh), the threat of inundation is necessarily a national preoccupation.

It is therefore natural that much interest should have been aroused by claims that there has been a "global" sea-level rise of $1 \mathrm{~mm}$ per year during the last century (Gornitz et al., 1982), that rates of 5 to $20 \mathrm{~mm} / \mathrm{yr}$ are likely during the next century as a result of climatic changes (Hoffman, 1984; Thomas, 1986), that a rapid $5 \mathrm{~m}$ rise in sea level due to melting of the West Antarctic ice sheet could be imminent or in progress within 50 years (Mercer, 1978), that the effects of accelerated melting of polar ice might already be visible in increased rates of sea-level rise since about 1940, and especially since 1970 (Etkins \& Epstein, 1982), and that following a time of "little or no change prior to the early 1900s", we have in fact been experiencing a sea-level increase averaging more than $2 \mathrm{~mm}$ per year for the last 50 years (Barnett, 1984). Probably, not all of these claims will eventually come to be viewed as correct; but they point to issues of importance and demand a close scrutiny of the available data.

This report offers an examination of tide-gauge data from stations having records of duration between 60 and 180 years, and identifies a number of potential pitfalls in the analysis of the data. Enhancements of the linear regression and empirical orthogonal function (EOF) analysis techniques usually applied to tide-gauge records are described and applied to the data. Also included are reassessments of conclusions that have previously been drawn on the basis of less complete information.

\section{Previous results}

Studies of secular trends in global tide-gauge data have usually been undertaken with the intent of learning something about absolute (in some sense) sea-level changes that are global in scale, as distinct from land-level changes and from sea-level changes that are due to a redistribution of water within the oceans. Such changes are traditionally referred to as "eustatic", a word that is frequently used in sea-level studies of all kinds and cannot be avoided here: see "Interpretation" for a more precise description of the concept. In estimating rates of eustatic change, it has been common to exclude from consideration records that show unusually large rates of uplift (especially those from Scandinavia, where many long-established tide-gauge stations are located) or subsidence.

The criteria for selecting stations vary between different publications (table 1). Some authors have even chosen to work with only a few "key" stations that they believe are 


\begin{tabular}{|c|c|c|c|c|c|c|}
\hline Author(s) & INCLUDEGTATIONS & SELECTIOQEXLLUED & $s \$ 2+18 \mathrm{ks}$ & Analysis & Years & Rate/mm $y^{-1}$ \\
\hline Gutenberg (1941) & $\begin{array}{l}\text { "suffictent data } \\
\text { available" }\end{array}$ & $\begin{array}{l}\text { stations in regions of } \\
\text { known post-glacial } \\
\text { uplift }\end{array}$ & 69 & $\begin{array}{l}\text { Average of reglonal } \\
\text { averages of linear trends }\end{array}$ & $1807-1939$ & $(1.1 \pm 0.8)^{\star}$ \\
\hline Mosby (1957) & $\ldots \ldots \cdots \cdots \cdots \cdots \cdots \cdots$ & $\cdots \cdots \cdots \cdots \cdots \cdots \cdots \cdots$ & $?$ & $\cdots \cdots \cdots \cdots \cdots \cdots \cdots \cdots \cdots \cdots \cdots \cdots$ & $? 1937-1957$ & 1.12 \\
\hline Lisitzin $(1958,1974)$ & $\begin{array}{l}\text { Brest } 1807-1943 \\
\text { Swinoujscie } 1811-1943 \\
\text { Lyokk1 1858-1943 } \\
\text { Jungfrusund } 1858-1943 \\
\text { Bombay } 1878-1943 \\
\text { Marse11les } 1891-1943\end{array}$ & $\ldots \cdots \cdots \cdots \cdots \cdots \cdots \cdots$ & 6 & $\begin{array}{l}\text { Average of trends after } \\
\text { removing pre-1891 trend }\end{array}$ & $1891-1943$ & $(1.23 \pm 0.41)^{*}$ \\
\hline $\begin{array}{l}\text { Fairbridge \& Krebs } \\
\text { (1962) }\end{array}$ & $\begin{array}{l}\text { "selected reliable } \\
\text { stations" }\end{array}$ & $\begin{array}{l}\text { tectonically unstable } \\
\text { areas and other obvi- } \\
\text { ously anomalous records }\end{array}$ & $?$ & 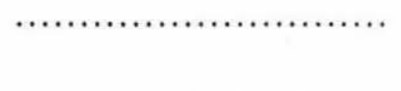 & $\begin{array}{l}1900-1950 \\
1946-1956\end{array}$ & $\begin{array}{l}1.2 \\
5.5\end{array}$ \\
\hline Emery $(1980)$ & $\begin{array}{l}\text { regression slope } \\
\text { significantly greater } \\
\text { than zero }\end{array}$ & $\begin{array}{l}\text { too short, } \\
\text { too interrupted, or } \\
\text { too irregular }\end{array}$ & $247^{* \pi}$ & Median of 1 inear trends & $1970-1974$ & $\begin{array}{l}3.0 \\
\text { (continents) } \\
2.5 \\
\text { (oceanic } \\
14 \text { islands) }\end{array}$ \\
\hline Klige (1982) & $\ldots \cdots \cdots \cdots \cdots \cdots \cdots \cdots$ & $\cdots \cdots \cdots \cdots \cdots \cdots \cdots$ & "many" & 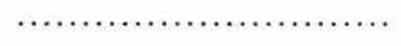 & $1900-1975$ & 1.5 \\
\hline Gornttz et al. (1982) & 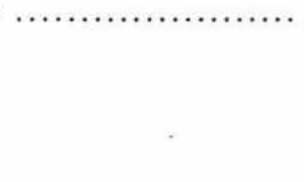 & $\begin{array}{l}\text { records shorter than } \\
20 \text { years, stations in } \\
\text { seismicaily active or } \\
\text { rapidly subsiding } \\
\text { localities, and the } \\
\text { isostaticaliy uplifting } \\
\text { region of Scandinaria }\end{array}$ & 193 & $\begin{array}{l}\text { Average of regtonal } \\
\text { averages of linear trends } \\
\text { Same, after removal of } \\
6000 \text {-year trends based on } \\
\text { Holocene shoreline } \\
\text { Indicators }\end{array}$ & $\begin{array}{c}; 880-1980 \\
n\end{array}$ & $\begin{array}{l}1.2 \\
1.0\end{array}$ \\
\hline \multirow[t]{2}{*}{ Barnett (1983) } & $\begin{array}{l}\text { selected regional } \\
\text { representatives } \\
\text { located away from }\end{array}$ & $\ldots \ldots \ldots \cdots \cdots \cdots \cdots \cdots$ & 9 & $\begin{array}{l}\text { Linear trend of first } \\
\text { principal component }\end{array}$ & $1903-1969$ & $1.51 \pm 0.15$ \\
\hline & $\begin{array}{l}\text { areas of strong } \\
\text { tectonic movement }\end{array}$ & & 7 & Same & $1930-1975$ & $1.79 \pm 0.22$ \\
\hline Barnett (1984) & $\begin{array}{l}\text { at least } 30 \text { years } \\
\text { of data }\end{array}$ & $\begin{array}{l}\text { Scandinavian \& Alaskan } \\
\text { stations neglected } \\
\text { because of uplift; } \\
\text { data omitted where } \\
\text { obvious problems exist }\end{array}$ & $155^{* *}$ & $\begin{array}{l}\text { Welghted average of regional } \\
\text { weighted averages, after } \\
\text { local averaging of records } \\
\text { in areas of high station } \\
\text { density }\end{array}$ & $\begin{array}{l}1881-1980 \\
1930-1980\end{array}$ & $\begin{array}{l}1.43 \pm 0.14 \\
2.27 \pm 0.23\end{array}$ \\
\hline Aubrey (1985) & $\cdots \cdots \cdots \cdots \cdots \cdots \cdots \cdots$ & $\cdots \cdots \cdots \cdots \cdots \cdots \cdots$ & $?$ & $\ldots \ldots \cdots \cdots \cdots \cdots \cdots \cdots \cdots \cdots \cdots \cdots \cdots \cdots \cdots$ & $\cdots \cdots \cdots$ & 0 to 3 \\
\hline \multirow[t]{4}{*}{$\begin{array}{l}\text { Gornttz \& Lebedeff } \\
(1987)\end{array}$} & $\begin{array}{l}\text { record length at } \\
\text { least } 20 \text { years }\end{array}$ & $\begin{array}{l}\text { stations with trends } \\
\text { exceeding } \pm 10 \mathrm{~m} V \mathrm{yr}\end{array}$ & 286 & 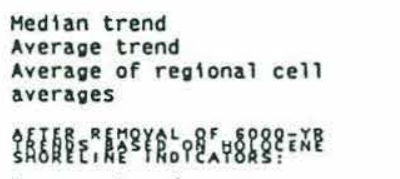 & $1880-1980$ & $\begin{array}{l}0.89 \\
0.61 \pm 0.37 \\
0.71 \pm 0.14\end{array}$ \\
\hline & & & 130 & $\begin{array}{l}\text { Average trend } \\
\text { Average of regional cell } \\
\text { averages }\end{array}$ & $\ddot{n}$ & $\begin{array}{l}1.20 \pm 0.25 \\
0.95 \pm 0.10\end{array}$ \\
\hline & $\begin{array}{l}\text { record length at } \\
\text { least } 20 \text { years }\end{array}$ & $\begin{array}{l}\text { Fennoscandia; } \\
\text { stations with trends } \\
\text { exceeding } 3 \text { standard } \\
\text { deviations }\end{array}$ & 231 & $\begin{array}{l}\text { Average trend } \\
\text { Average of reglonal cell } \\
\text { averages (excluding two in } \\
\text { the Arctic) }\end{array}$ & $\ddot{n}$ & $\begin{array}{l}1.68 \pm 0.32 \\
1.66 \pm 0.37\end{array}$ \\
\hline & & & & $\begin{array}{l}\text { [Average?] trend relative } \\
\text { to } 1880-1931\end{array}$ & $1932-1982$ & 0.59 \\
\hline This paper & . & & 28 & $\begin{array}{l}\text { Average of trends based } \\
\text { on quadratic model }\end{array}$ & $\begin{array}{l}+1880 \\
+1930 \\
+1980\end{array}$ & $\begin{array}{l}0.64 \pm ? \\
1.18 \pm ? \\
1.72 \pm ?\end{array}$ \\
\hline
\end{tabular}

"Trends computed by Gutenberg's approximate method instead of by linear regression
m Includes stations that did not enter into the rate calculation

+ Based on data covering a longer time interval

Table 1: Global averages of the rate of sea-level rise, and estimates of the eustatic contribution (once considered to be the same thing, and not discriminated here). 
most likely to yield information about the eustatic rise (Lisitzin, 1958; Fairbridge \& Krebs, 1962; Barnett, 1983). Despite the differing criteria, and despite differences in the time intervals considered and the analytical techniques employed, most estimates of the rate of eustatic sea-level rise over intervals of several decades or more fall between 0.6 and $1.8 \mathrm{~mm}$ per year. Further narrowing of this range on the basis of tide-gauge data alone appears unlikely. For one thing, efforts to derive a truly representative global average are hampered by the uneven geographical distribution of the data, which is heavily weighted in favor of the northern hemisphere, particularly Europe, North America, and Japan. Just as importantly, an estimate of eustatic sea-level change based on an average of relative sea-level changes pre-supposes that other factors affecting RSL trends (such as the vertical movements of the earth's crust) do not contribute significantly to their average value either at the time under study or, as in the investigations by Lisitzin (1958) and by Gornitz et al. (1982), during some earlier interval. The validity of this assumption is by no means certain and arouses considerable debate.

Table 1 lists estimates of the rate of either eustatic or "global" sea-level rise based on tide-gauge data with global coverage. Estimates made prior to 1982 may be considered obsolete because they were based on data sets that are now well out of date, or were not representative of the entire data set available. A closer examination of the more recent results is included below under "Interpretation", following a new derivation of estimates for the single years 1880,1930 , and 1980 .

Estimates of the rate of eustatic sea-level rise have been supplemented over the years by observations concerning its rate of change and concerning possible increases or decreases on shorter time scales (5 to 20 years). Gutenberg (1941) was already aware when he published the first geodetic estimate of global sea-level rise that the rate might be increasing: "it seems as if the rising has occurred at a faster rate during recent decades." Lisitzin (1958) found the rate of rise between 1891 and 1943 to be $1.12 \pm 0.36 \mathrm{~mm} / \mathrm{yr}$ greater than that before 1891. Fairbridge \& Krebs (1962) said that sea level was at its "lowest point" about 1890, but had scant evidence of an earlier worldwide fall. Barnett (1983) first found "no suggestion that the trend of MSL [mean sea level] has been increasing significantly in recent years", but later in a more comprehensive survey (Barnett, 1984) identified "times of little change (1881-1920) and steady increase (1920-1980)." Gornitz \& Lebedeff (1987) also recognized an increase in trend between the intervals 1880-1931 and 1932-1982, but doubted its significance. These findings do not reveal conclusively whether the rate of eustatic sea-level rise is increasing or remaining approximately the same. 
Examples of suspected increases or decreases in the global RSL trend on time scales of 5 to 20 years are found in the work of Fairbridge \& Krebs (1962), who noted a "phenomenal mean rise of $5.5 \mathrm{~mm}$ per year" from 1946 to 1956, and Emery (1980), who found that the RSL rise for 1970-1974 was much larger than that computed from full-length records. These sharp deviations from the prevailing global trend are not much evident in later publications, and certainly have not been sustained. Spurious trends of this sort can result if the most recent data are regionally biased, because regional trends are likely to be influenced more strongly by local factors (tectonic, isostatic, oceanographic, etc.) than by eustatic SL rise. In any case these and other examples make clear the undesirability of determining long-term RSL trends from data spanning short time intervals (Gornitz et al., 1982).

The 5- to 20-year fluctuations represented in long-term global sea-level curves of various authors show better agreement, and are more suitable for identifying systematic deviations from the average trend, if any exist. Such a curve, published by Fairbridge \& Krebs (1962), was compared with the sunspot cycle and later (Etkins \& Epstein, 1982) with a curve representing global mean temperature. Updated sea-level curves prepared by Gornitz et al. (1982) and Klige (1982) are compared with temperature and other contributing factors in a paper by Robin (1986). The suggestion by Kalinin \& Klige (1978) and Gornitz et al. (1982) that temperature changes are mimicked after an 18- or 19-year lag by changes in sea level is barely supported by the sea-level curve of the latter authors (as they recognized) - but it appears to be vindicated remarkably by Klige's curve. Why this is so remains an open question.

More advanced analytical methods are now being employed in sea-level studies. Barnett (1983) undertook a rigorous statistical analysis of tide-gauge data, in which the global pattern was represented by the first principal component of 9 data series covering 1903-1969, and separately of 7 data series covering 1930-1975. The results provide an alternative to the average curves prepared by other authors (see explanation under "Empirical orthogonal function (EOF) analysis" below). Barnett displayed only one mode of variability, however, and did not verify the statistical significance of deviations from the linear trend which dominated the time-dependence. He later applied similar methods to a much more extensive data set (Barnett, 1984). A seemingly more fruitful application of the method is found in the work of Aubrey and Emery (e.g., Aubrey, 1985), who have had some success in matching the spatial and temporal structure of various geophysical controls to regional sea-level patterns by a closer examination of the first few (dominant) empirical orthogo- 
nal functions. They hope that, in addition to relating sea levels to local geological and oceanographic influences, they will acquire enough understanding of this "noise" to allow the eustatic "signal" to be interpreted with greater statistical confidence.

As this survey demonstrates, the idea that sea levels are, even before the definite identification of a $\mathrm{CO}_{2}$-induced global warming, already rising more quickly than 50 or 100 years ago is neither proven nor universally held. In fact, some authors believe that RSL trends may now be decreasing (Lamb, 1982; Robin, 1986) - but no quantitative studies were found that reached this conclusion.

Eustatic sea-level changes before about 1880 cannot be estimated reliably from tide gauges because few had been installed outside Europe. Consequently, there have been few attempts to extrapolate the eustatic SL curve further into the past using geodetic data. Nevertheless, Fairbridge (1961) used measurements from a single tide gauge at Amsterdam, said to be the longest record available, to deduce eustatic SL changes from 1682 to 1930. His curve shows little variation until about 1770 and a decline until about 1810 , followed by another interval of little change and a rise after 1870 . The range is about $0.06 \mathrm{~m}$.

\section{Data coverage}

The Committee on Mean Sea Level and its Variations (now the Permanent Service for Mean Sea Level, PSMSL) was set up in 1933 and currently holds data from over 1200 tidegauge stations around the world. Data used in this study were annual means furnished on magnetic tapes by the PSMSL, courtesy of its director, Dr. D.T. Pugh. With good datum control, an annual mean can generally be considered accurate to about $1 \mathrm{~mm}$ (IAPSO, 1985).

One way of improving the data coverage over that of earlier studies of this kind is to adjust the mathematical modelling procedure to allow for suspected sudden changes of base level in records that would otherwise be considered too suspicious for inclusion of the full record (e.g., Sydney, San Diego). For present purposes, every data series is extracted from an individual record on the PSMSL "Metric" or "RLR" (revised local reference) tape. Sudden changes of level strongly suggestive of base-level changes are not found in the data selected, except at San Francisco, where reasons for believing the pieced-together series to be matched correctly are given by Smith (1980). The mathematical techniques described in this paper would accomodate such changes, however, if they were thought to exist.

Three groups of tide-gauge stations were selected for analysis (table 2). The primary 


\begin{tabular}{|c|c|c|c|c|c|c|c|}
\hline & & STATION & COUNTRY & 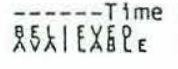 & 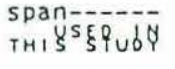 & 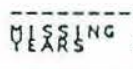 & MM/rk' \\
\hline \multirow{15}{*}{\multicolumn{2}{|c|}{ Group 1}} & AMSTERDAM & NETHERLANDS & $1682-1863$ & & & \\
\hline & & STOCKHOLM & SWEDEN & $1774-1981$ & $1889-1981$ & 0 & $-4.22 \pm 0.29$ \\
\hline & & BREST & FRANCE & $1807-1984$ & $1865-1981$ & 9 & $1.22 \pm 0.14$ \\
\hline & & SWINOUJSCIE & POLAND & $1811-1982$ & $1882-1943$ & 0 & $1.02 \pm 0.38$ \\
\hline & & WISMAR & GERMANY (E.) & $1812-1980$ & $1882-1943$ & 0 & $1.45 \pm 0.36$ \\
\hline & & DEN HELDER & NETHERLANDS & $1832-1984$ & $1865-1980$ & 1 & $1.34 \pm 0.14$ \\
\hline & & NEW YORK & U.S.A. & $1843-1980$ & & & \\
\hline & & HELLEVOETSLUIS & NETHERLANDS & $1848-1984$ & $1865-1967$ & 0 & $1.56 \pm 0.17$ \\
\hline & & HALIFAX & CANADA & $1851-1980$ & $1897-1980$ & 22 & $3.67 \pm 0.21$ \\
\hline & & SAN FRANCISCO & U.S.A. & $1854-1983$ & $1865-1980$ & 0 & $1.11 \pm 0.15$ \\
\hline & & WARNEMÜNDE & GERMANY (E.) & $1856-1980$ & $1882-1943$ & 0 & $1.42 \pm 0.31$ \\
\hline & & HELSINKI & FINLAND & $1858-1978$ & $1879-1976$ & 0 & $-2.87 \pm 0.30$ \\
\hline & & CHERBOURG & FRANCE & $1860-1984$ & & & \\
\hline & & ABERDEEN & U.K. & $1862-1981$ & $1865-1965$ & 1 & $0.64 \pm 0.14$ \\
\hline & & VLISSINGEN & NETHERLANDS & $1862-1984$ & $1865-1980$ & 0 & $1.08 \pm 0.21$ \\
\hline \multirow{20}{*}{\multicolumn{2}{|c|}{ Group 2}} & KARACHI & PAKISTAN & $1868-1982$ & & & \\
\hline & & VENEZIA & ITALY & $1872-1984$ & & & \\
\hline & & SYONEY & AUSTRALIA & $1873-1985$ & $1897-1982$ & 0 & $0.63 \pm 0.18$ \\
\hline & & ALICANTE & SPAIN & $1874-1978$ & & & \\
\hline & & ВОМВАY & INDIA & $1878-1964$ & $1878-1962$ & 0 & $1.29 \pm 0.17$ \\
\hline & & ADEN & ADEN & $1879-1969$ & $1879-1969$ & 33 & $3.35 \pm 0.17$ \\
\hline & & RANGOON & BURMA & $1880-1962$ & & & \\
\hline & & CALCUTTA & INDIA & $1881-1964$ & & & \\
\hline & & CASCAIS & PORTUGAL & $1882-1984$ & $1882-1979$ & 4 & $1.23 \pm 0.18$ \\
\hline & & GENOVA & ITALY & $1884-1982$ & $1884-1982$ & 22 & $1.29 \pm 0.12$ \\
\hline & & MARSEILLE & FRANCE & $1885-1984$ & $1885-1963$ & 4 & $1.66 \pm 0.20$ \\
\hline & & SETE & FRANCE & $1888-1979$ & & & \\
\hline & & PORT VENDRES & FRANCE & $1888-1983$ & & & \\
\hline & & LA GOULETTE & TUNISIA & $1889-1957$ & & & \\
\hline & & BÖNE & ALGERIA & $1889-1959$ & & & \\
\hline & & ORAN & ALGERIA & $1890-1959$ & & & \\
\hline & & HOSOJIMA & JAPAN & $1894-1984$ & $1900-1983$ & 4 & $0.55 \pm 0.39$ \\
\hline & & TONOURA & JAPAN & $1894-1982$ & & & \\
\hline & & WAJIMA & JAPAN & $1894-1984$ & $1900-1983$ & 0 & $0.41 \pm 0.32$ \\
\hline & & ST. JOHN N.B. & CANADA & $1894-1980$ & & & \\
\hline \multirow{8}{*}{\multicolumn{2}{|c|}{ Group 3}} & SEATTLE & U.S.A. & $1899-1983$ & $1889-1979$ & 0 & $1.90 \pm 0.20$ \\
\hline & & MANILA & PHILLIPINES & $1901-1984$ & $1902-1981$ & 21 & $4.14 \pm 0.62$ \\
\hline & & BUENOS AIRES & ARGENTINA & $1905-1982$ & $1905-1980$ & 13 & $1.10 \pm 0.33$ \\
\hline & & HONOLULU & U.S.A. (HAWAII) & $1905-1980$ & $1905-1980$ & 0 & $1.58 \pm 0.26$ \\
\hline & & SAN DIEGO & U.S.A. & $1906-1983$ & & & \\
\hline & & GALVESTON & U.S.A. & $1908-1980$ & $1909-1978$ & 1 & $6.31 \pm 0.42$ \\
\hline & & BALBOA & PANAMA & $1908-1969$ & $1908-1969$ & 0 & $1.57 \pm 0.27$ \\
\hline & & CRISTOBAL & PANAMA & $1909-1969$ & $1909-1969$ & & $1.10 \pm 0.21$ \\
\hline
\end{tabular}

Table 2: Tide-gauge stations with records of long duration qualifying for inclusion in the study. With few exceptions (Amsterdam, Aden, Rangoon, La Goulette, Bône, Oran, Cristobal) all of the gauges listed are probably still operational. 
group of stations includes those where available records began prior to 1865 and existed for at least 120 years. After discarding records which were deemed unsuitable because data for too many years were missing (Sheerness, Le Havre), 15 such stations were identified; of these, 12 are located in northern Europe, the others in North America. To help to offset the geographical imbalance, different criteria were adopted for stations outside northern Europe. Thus a second list was compiled, of stations with records begun prior to 1895 and continuing for at least 60 years. This second group includes stations from five continents and improves the spatial distribution substantially. Finally, a group of 10 stations in areas still under-represented was added, allowing only those with records begun prior to 1910 and continuing for at least 60 years.

From the list of stations in table 2, largely complete and unbroken data series from 28 stations were available on either the "Metric" or "RLR" tape and were incorporated into the study. The availability of data by station and year is represented in fig. 1, and the locations of the 28 stations are shown on the world map in fig. 2 .

A variety of corrections can be applied to relative sea-level data, to remove the effects of well-understood phenomena. Commonly the changing spatial distribution of atmospheric pressure, which results (among other things) in a proportional depression of the sea surface known as the "inverted barometer effect", is adjusted for, where barometric measurements have been made over the same time interval. About $5 \%$ of the observed variability at Bombay, for example, is said to be removed by this step (Fairbridge \& Krebs, 1962). Changes in the Moon's declination (the tilt of its orbit relative to the Earth's equator, which departs from its mean value by more than $5^{\circ}$ ) also affect the distribution of sealevel heights, giving rise to the so-called "nodal tide" with a period of 18.6 years and a theoretical amplitude of more than $7 \mathrm{~mm}$ at latitude $60^{\circ}$ (Lisitzin, 1974, pp. 39-41). A correction for the equilibrium nodal tide, which can be predicted easily, is possible, but the observed amplitude of the 18.6-year tidal constituent exceeds the predicted value by a factor of about 4 and the evidence for its equilibrium nature is generally weak, even though the period is long enough for the attainment of equilibrium to be expected. The correction is appropriate if the equilibrium nodal tide is simply being masked by other fluctuations, but not if, as Lisitzin (1974, p. 49) says is probable, "the highly complicated shapes of the oceans and seas" are responsible for distorting the tide.

Another type of correction, based on Holocene shoreline indicators, is effective in removing longer-term (e.g., 6000-year) trends and was investigated by Gornitz et al. (1982) and Gornitz \& Lebedeff (1987). In the present study, no corrections of the types just 


\section{DATA COVERAGE}

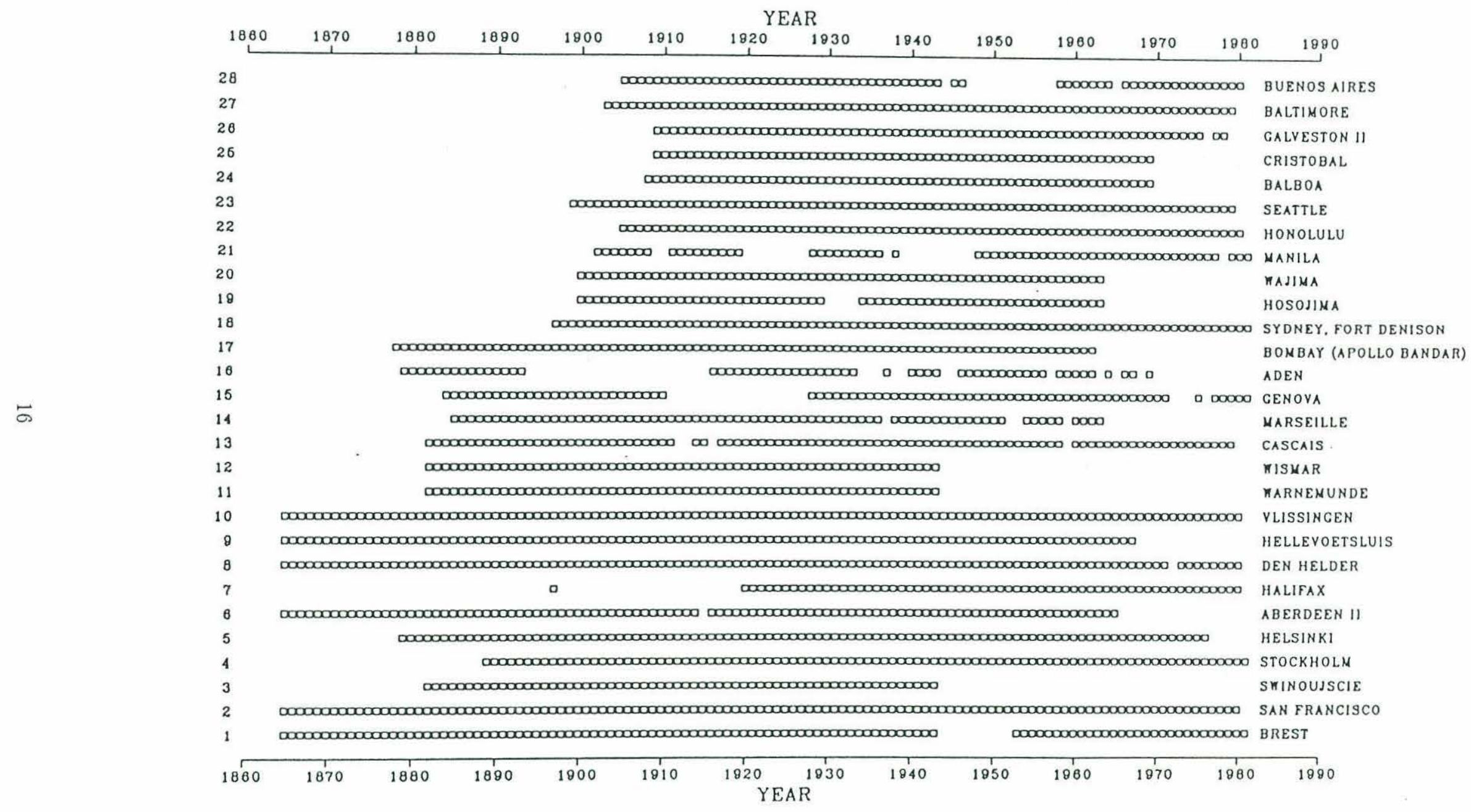

Figure 1: The 28 tide-gauge stations included in the study, and the years of data utilized. 


\section{LOCATIONS OF SEA-LEVEL STATIONS}

$$
\text { - = RLR } \circ=\text { Other }
$$

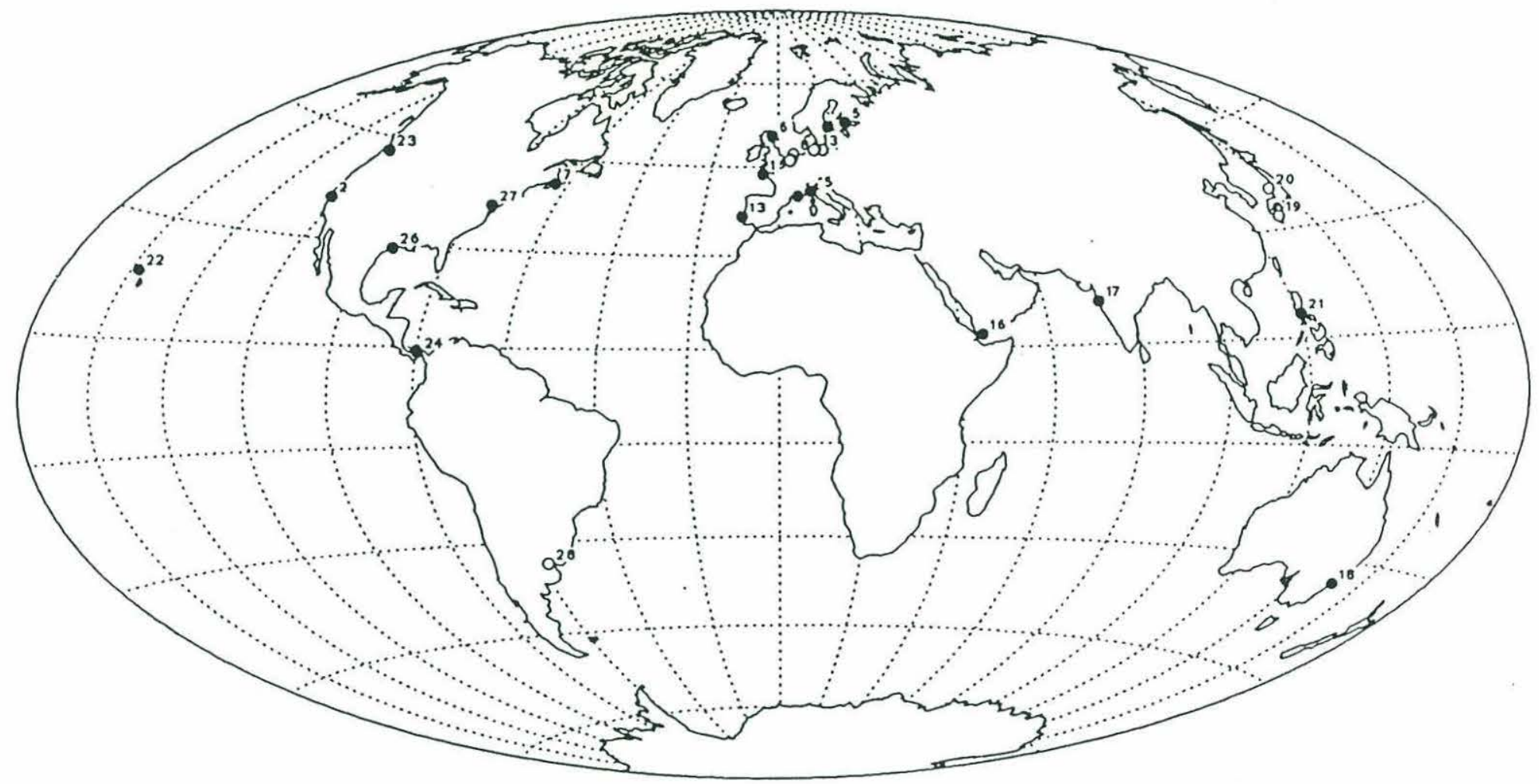

Figure 2: Locations of the 28 tide-gauge stations listed in figure 1. 
discussed have been applied to the data, with the result that all of the possible causes of RSL change are weighed against each other in the analysis and must be considered when interpreting the results.

The strategy I have adopted to characterize the RSL data set under study entails (i) identification and removal of long-term (quadratic) trends at each station on the grounds that their long time scale and fundamentally simple form make it possible to consider their physical interpretation separately from any short-term variability that might be related to them, (ii) inspection of the "global" mean residual curve to decide whether it warrants removal prior to EOF analysis of the residuals, and (iii) EOF analysis of the residual data, or subsets of it, to match up the spatial and temporal patterns of change responsible for the greatest part of the observed variability. Given sufficient data, the regression coefficients, the coefficients of, say, the first two EOF's, and the residual variance at each station, plus the variabilty of the global mean residual (if significant), could be expected to provide an adequate basis for interpreting the spatial distribution of whatever "global" mechanisms might contribute significantly to RSL records.

\section{Trend analysis and removal}

Methods. The regression analysis described in this section yields estimates of RSL trends, of their rates of change, and of suspected changes of reference level; it also makes possible the plotting of confidence intervals and joint confidence regions for these parameters.

An individual series of discretely sampled RSL measurements will be indicated symbolically as either a function of time $y=y(t)$ or a row vector $\mathbf{y}$ with $N$ elements (a $1 \times N$ matrix). Matrix expressions are illustrated by a numerical example in appendix 1 . We may remove at the outset the temporal mean value $\bar{y}$ and then confine our attention to the residuals which may be designated $\tilde{y}(t)$ so that

$$
y(t)=\bar{y}+\tilde{y}(t) .
$$

When $\tilde{y}$ is plotted against $t$ (see fig. 3 ) an increasing, or sometimes decreasing, trend is usually apparent, and we might wish to evaluate this by fitting a straight line. The best fitting line, found by least-squares linear regression, has the slope $b=\Sigma \tilde{x} \tilde{y} / \Sigma \tilde{x}^{2}$ where $\tilde{x}$ is the time coördinate with mean removed, the summation being over all values of $t$. Trends determined in this way are included in table 2. 

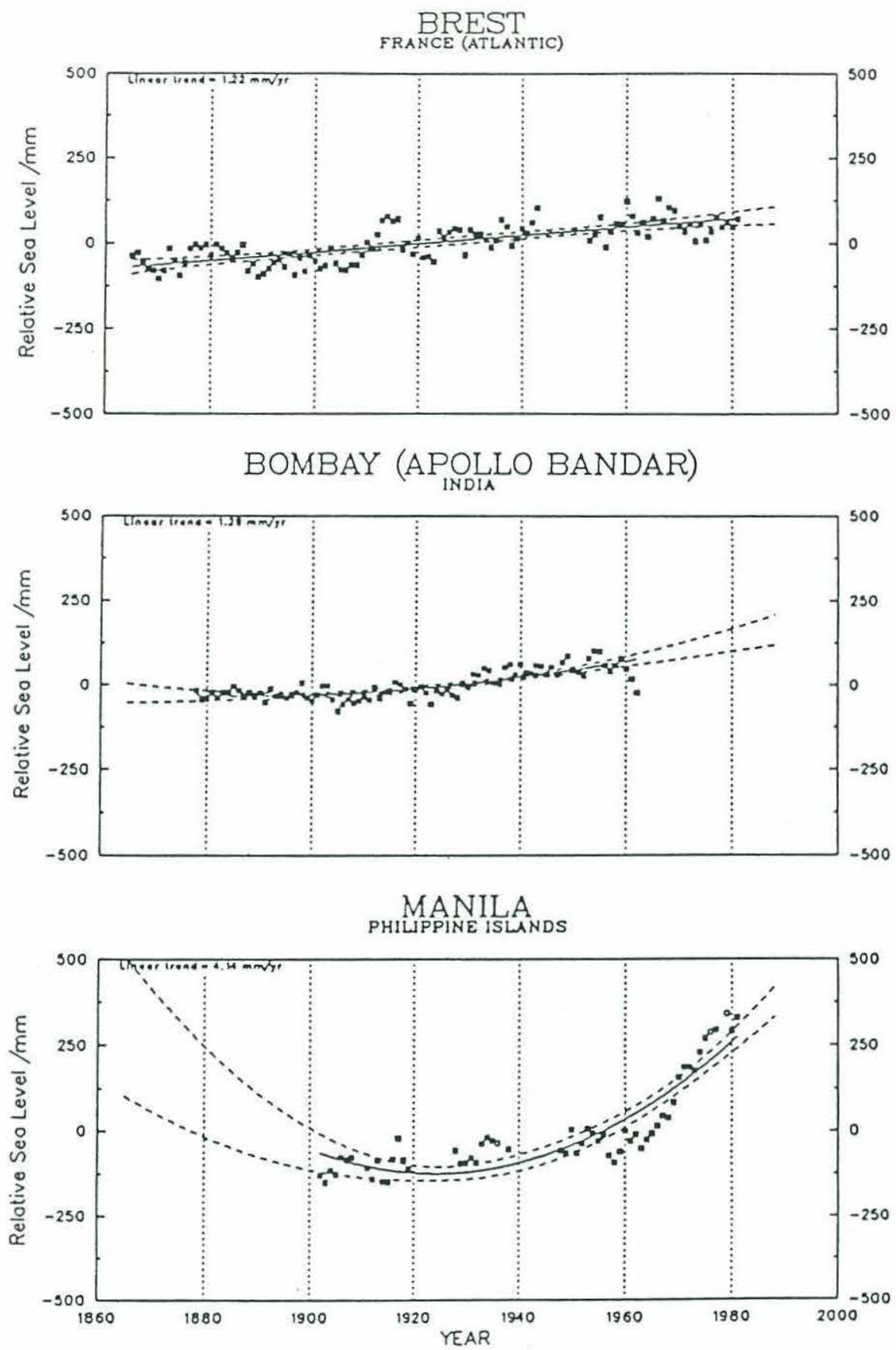

Figure 3: Sample plots of annual mean sea-level elevation relative to its mean value. Quadratic regression curve (solid line) with $95 \%$ confidence band (bounded by dashed line) is shown on each plot. 
Averaging and the extraction of linear trends are special cases of the general leastsquares regression procedure by which curves of any prescribed shape are fitted to a data set. This procedure determines coefficients $b_{0}, b_{1}$, etc., so that a data series can be expanded as

$$
y(t)=b_{0} f_{0}(t)+b_{1} f_{1}(t)+\cdots+a(t)
$$

in a way that minimizes the residual function $a(t)$ and maximizes the proportion of the total variability accounted for by multiples of the prescribed functions $f_{j}(t)$. After the temporal average values (which is meaningless in this study) has been discarded, obtaining physically interesting results from a regression analysis requires choosing functions to which physical significance can be attached - and which also "explain" as much of the observed variability as possible. The significance of linear trends is evident from visual inspection of the data, and there are certainly physical processes with time scales greater than 100 years, to which a "linear" RSL trend can be ascribed. But inspection also reveals that more complicated shapes, allowing for gradual changes in the rate of rise, would usually give a better fit, and these shapes appear to have much in common on a regional scale at least. In general, the shapes show variability on time scales as short as 20 to 40 years (or less) and require objective means of identification, which are the subject of the next section. Even so, there is one prominent feature - a widespread increase in the rate of rise over the entire length of available record - which has been perceived by many authors (cited previously) and which has often been linked with a global climatic warming trend. If this change in trend is genuine and worldwide it should be detectable ("noise" permitting) by fitting to the data a curve with a non-zero second derivative. The smoothest such curve is a parabolic arc.

These considerations suggest seeking a parabolic or "quadratic" fit to each data series, and comparing the results to test the idea that RSL rise is gradually becoming more rapid. We therefore seek coefficients $b_{0}, b_{1}, b_{2}$ such that

$$
\tilde{y}=b_{0}+b_{1} \tilde{x}+b_{2} \tilde{x}^{2}+\text { residual, }
$$

where the residual is to be minimized. Before we see how the fit is obtained, however, let us look at another useful modification.

Regression analysis can do more than just estimate trends. It can also be used to allow for changes in the reference level (gauge zero) from which the sea-surface elevation is measured. Suppose, for example, that 110 years of observations are available from a particular tide-gauge station, but the reference level is believed to have been different 
during the first 40 years than during the last 70 . Such discrepancies are often obvious by inspection: a sudden RSL change of 1 meter, which may be indicated by the raw data, is hardly possible unless a major earthquake has occurred nearby, and in all probability the actual difference lies within a considerably smaller range. Mathematically, the only new aspect is that the constant $b_{0}$ in the last equation will not have the same value over the entire time domain. Instead, it is appropriate to look for separate constants $b_{01}$ for the first 40 years and $b_{02}$ for the last 70 , each being the coefficient of a function that is 1 in one subset of the time domain, and 0 elsewhere. It is important to realize that no assumptions are made regarding the difference between $b_{01}$ and $b_{02}$; the analysis accounts for all possible values of the two constants, subject to the quadratic model already assumed. The results not only give the values of $b_{01}$ and $b_{02}$ that best conform to the model, but also, as discussed later in this section, tell how all the parameter estimates $b$ are jointly distributed.

There may be any number of reference levels, and we need a general expression. Let $\bar{y}(t)$ denote the series of measurements after mean values have been removed over each subset of the time domain separately. Let the subsets of the time domain have indices $1, \ldots, k$ so that

$$
\tilde{y}=b_{01} h_{1}(t)+\cdots+b_{0 k} h_{k}(t)+b_{1} \tilde{x}+b_{2} \tilde{x}^{2}+\text { residual }
$$

where

$$
h_{i}(t)= \begin{cases}1 & \text { within the } i \text { th sub-domain } \\ 0 & \text { otherwise. }\end{cases}
$$

In general, the least-squares solution of the overdetermined problem

$$
\mathrm{bF}=\left[\begin{array}{llll}
b_{0} & b_{1} & \cdots & b_{n}
\end{array}\right]\left[\begin{array}{c}
----f_{0}(t)---- \\
----f_{1}(t)---- \\
\vdots \\
----f_{n}(t)----
\end{array}\right]=[----\tilde{y}(t)----]
$$

is found by solving $\mathbf{b F F} \mathbf{F}^{\dagger}=\tilde{\mathbf{y}} \mathbf{F}^{\dagger}$ (where ${ }^{\dagger}$ denotes matrix transposition), so setting $f_{0}=1$, $f_{1}=\tilde{x}$, and $f_{2}=\tilde{x}^{2}$,

$$
\left[\begin{array}{lll}
b_{0} & b_{1} & b_{2}
\end{array}\right]\left[\begin{array}{ccc}
N & \Sigma \tilde{x} & \Sigma \tilde{x}^{2} \\
\Sigma \tilde{x} & \Sigma \tilde{x}^{2} & \Sigma \tilde{x}^{3} \\
\Sigma \tilde{x}^{2} & \Sigma \tilde{x}^{3} & \Sigma \tilde{x}^{4}
\end{array}\right]=\left[\begin{array}{lll}
\Sigma \tilde{y} & \Sigma \tilde{x} \tilde{y} & \Sigma \tilde{x}^{2} \tilde{y}
\end{array}\right]
$$


when a single reference level is used. With a suitable notation, a corresponding equation that allows for $k$ reference levels could easily be written. Employing this equation (not shown) and noting that $\Sigma \tilde{y}$ is zero, the coefficients are found to be

$$
\begin{aligned}
b_{2} & =\frac{\left(\Sigma \tilde{x}^{2}-\langle\tilde{x}\rangle_{i} \Sigma_{i} \tilde{x}\right) \Sigma \tilde{x}^{2} \tilde{y}-\left(\sum \tilde{x}^{3}-\langle\tilde{x}\rangle_{i} \Sigma_{i} \tilde{x}^{2}\right) \Sigma \tilde{x} \tilde{y}}{\left(\Sigma \tilde{x}^{2}-\langle\tilde{x}\rangle_{i} \Sigma_{i} \tilde{x}\right)\left(\Sigma \tilde{x}^{4}-\left\langle\tilde{x}^{2}\right\rangle_{i} \Sigma_{i} \tilde{x}^{2}\right)-\left(\Sigma \tilde{x}^{3}-\langle\tilde{x}\rangle_{i} \Sigma_{i} \tilde{x}^{2}\right)^{2}} \\
b_{1} & =\frac{\sum \tilde{x} \tilde{y}}{\Sigma \tilde{x}^{2}-\langle\tilde{x}\rangle_{i} \Sigma_{i} \tilde{x}}-b_{2} \frac{\Sigma \tilde{x}^{3}-\langle\tilde{x}\rangle_{i} \Sigma_{i} \tilde{x}^{2}}{\Sigma \tilde{x}^{2}-\langle\tilde{x}\rangle_{i} \Sigma_{i} \tilde{x}} \\
b_{0 i} & =-b_{1}\langle\tilde{x}\rangle_{i}-b_{2}\left\langle\tilde{x}^{2}\right\rangle_{i} .
\end{aligned}
$$

In equations (2), but not elsewhere, $\Sigma_{i}$ designates a sum over the $i$ th subset of the time domain rather than a sum over $\operatorname{mdex} i .\langle\rangle_{i}$ denotes an average over the indexed subset of the time domain, and the convention is adopted that products in which the index $i$ appears more than once are to be summed over all values $1, \ldots, k$ of the index. When all data are referred to a common reference level, simplification of the above formulae can be achieved by removing the subscripts $i$ and making the substitutions $\Sigma \tilde{x}=0,\langle\tilde{x}\rangle=0$, $\left\langle\tilde{x}^{2}\right\rangle=\Sigma \tilde{x}^{2} / N$.

The decomposition of $\tilde{\mathbf{y}}$ thus obtained (quadratic + residual) is $\tilde{\mathbf{y}}=\mathbf{b F}+\mathbf{a}$. To ascertain the meaningfulness of this decomposition, we first suppose each data series to be a sample of the multivariate (vector) random variable

$$
\eta=\beta_{0} \mathbf{f}_{0}+\beta_{1} \mathbf{f}_{1}+\cdots+\beta_{n} \mathbf{f}_{n}+\alpha
$$

where the $\beta$ 's are fixed but unknown parameters (which may be different for each series) and $\alpha$ is a multivariate normal random variable with zero mean and covariance matrix $\sigma^{2} \mathbf{I}$. The possibility that the sampled $\alpha$ itself includes (by chance) a linear or quadratic trend introduces uncertainty in the estimates, $\mathbf{b}$, of the model parameters, $\boldsymbol{\beta}$, and implies that some of the random variability may have been incorporated into bF rather than a. These difficulties are accounted for by the degrees of freedom as shown in the analysis-of-variance table (table 3 ).

Once the residual variance $s^{2}$ (estimated $\sigma^{2}$ ) is found from the analysis-of-variance table, the distribution of errors in the regression parameters $b$ or in their combinations can be stated in terms of its square root $s$. It can be shown that any linear combinations of the $n$ regression parameters - say, bZ, where $\mathrm{Z}$ is a matrix of $n$ rows - have a multivariate normal distribution with mean $\beta \mathbf{Z}$ and covariance matrix $\sigma^{2} \mathbf{Z}^{\dagger}\left(\mathbf{F F}^{\dagger}\right)^{-1} \mathbf{Z}$. Consequently any individual combination bz (where $\mathbf{z}$ is a column of $\mathbf{Z}$ ) is distributed as

$$
\mathrm{bz}=\beta \mathrm{z}+s \sqrt{\mathrm{z}^{\dagger}\left(\mathrm{FF}^{\dagger}\right)^{-1} \mathrm{z}} t_{N-k-2}
$$




\begin{tabular}{|c|c|c|c|c|}
\hline COMPONENT & ESTIMATE & SUM OF SQUARED ESTIMATES & D.O.F. & ESTIMATED VARIANCE \\
\hline Quadratic trend $\beta \mathrm{F}$ & $\mathrm{bF}$ & $\mathrm{bFF}^{\dagger} \mathrm{b}^{\dagger}=$ & $2+(k-1)$ & \\
\hline Residual $\alpha$ & $\mathrm{a}=\tilde{\mathrm{y}}-\mathrm{bF}$ & $\mathbf{a} \mathbf{a}^{\dagger}=\tilde{\mathbf{y}} \tilde{\mathbf{y}}^{\dagger}-\mathbf{b}\left(\tilde{\mathbf{y}} \mathbf{F}^{\dagger}\right)^{\dagger}$ & $N-2-k$ & $s^{2}=\mathbf{a a}^{\dagger} /(N-2-k)$ \\
\hline Total $\eta$ & $\tilde{\mathrm{y}}$ & $\overline{\mathbf{y}} \tilde{\mathbf{y}}^{\dagger}$ & $N$ & \\
\hline
\end{tabular}

Table 3: Analysis of variance: matrix computational formulae for a quadratic regression, with allowance for $k \geq 1$ different reference levels (for which corrections are included in the 'trend' estimate). D.O.F. = degrees of freedom. Estimated regression parameters in the matrix $\mathrm{b}$ are calculated from eq. (2). Notice that computation of the estimates (bF and a) themselves is not necessary to complete the rest of the table.

where $t_{N-k-2}$ is Student's ' $t$ ' random variable with $N-k-2$ degrees of freedom ( $c f$. Draper \& Smith, 1981, p. 94). Confidence limits are found by inserting the appropriate percentage point of the $t_{N-k-2}$ distribution. It can further be shown that a curve bounding the confidence region for any pair of such combinations, $\mathbf{b Z}$ (where $\mathbf{Z}$ is a $(k+2) \times 2$ matrix), is given by the parametric equation

$$
\mathbf{b Z}-\boldsymbol{\beta Z}=\sqrt{2} s F_{2, N-k-2}^{1 / 2}\left[\begin{array}{cc}
\cos \theta & \sin \theta
\end{array}\right]\left\{\mathbf{Z}^{\dagger}\left(\mathbf{F} \mathbf{F}^{\dagger}\right)^{-1} \mathbf{Z}\right\}^{1 / 2}
$$

in which $\mathrm{F}_{2, N-k-2}$ is any desired percentage point of the variance-ratio distribution (Fisher's ' $F$ ' distribution) with 2 and $N-k-2$ degrees of freedom, and $\theta$ assumes all values between 0 and $2 \pi$.

These formulae can be used to plot confidence limits, confidence bands, and confidence regions for estimates of the model quantities, and these in turn can be used to test ideas about the parameters contained in the model. The problem of determining the present RSL trend and its rate of change at individual stations provides a good example of how this technique can be employed. Under the assumptions built into the model (3), the RSL trend and its derivative at any time $\tau$ are given by

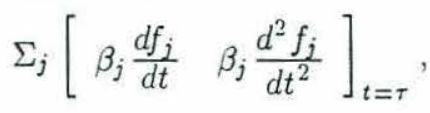

so substitution of the matrix

$$
\mathrm{Z}=\left[\begin{array}{ll}
\frac{d f_{0}}{d t} & \frac{d^{2} f_{0}}{d t^{2}} \\
\frac{d f_{1}}{d t} & \frac{d^{2} f_{1}}{d t^{2}} \\
\frac{d f_{2}}{d t} & \frac{d^{2} f_{2}}{d t^{2}}
\end{array}\right]_{t=\tau}=\left[\begin{array}{cc}
0 & 0 \\
1 & 0 \\
2 \tilde{x}(\tau) & 2
\end{array}\right]
$$

(with additional rows of zeroes added if $k>1$ ) into eqn. (5) allows plotting of confidence regions for these quantities, centered on the estimates $\mathrm{bZ}$. This has been done for all of the 
stations used in this study, taking $\tau=1987$. Other applications of the preceding formulae $(4,5)$ appear without further comment on their implementation.

Once a scalar parameter $\beta z$, such as the 1st derivative of the quadratic regression curve, has been estimated at each station, a spatial average of the parameter can be computed using any desired weighting factors. An equally weighted average of the RSL trends at all 28 stations is listed in table 1 for 1880,1930 , and 1980. The geographic imbalance and the absence of error margins should warn against basing any conclusions on these particular numbers, though. Standard errors or confidence intervals could have been found by the usual method of treating the trend estimates as if they were known quantities, but the uncertainty in the estimates is probably great enough, when a 2nd derivative is allowed for, that it must be taken into account. The essential tool needed to do so is a "random-effects model" in which the elements of $\boldsymbol{\beta}$ are treated as normally distributed random variables and from which the distributions of the appropriate statistics can be derived. This model is described by Snedecor \& Cochran (1980, ch. 13), but their discussion is limited to twostage averaging of data series having equal variance. Generalization to the averaging of trend estimates from series with unequal variance would yield the desired confidence limits, but is left for future development along with the consideration of weighting schemes, which would then be wanted to reduce further the bias due to poor spatial sampling.

Results. The residual variance (after quadratic trend removal) is plotted in fig. 4 against the linear trend estimate (from table 1), which adequately represents the average trend over the time spanned by each set of observations. This plot illustrates how the magnitudes of the trend and the "noise" obscuring it vary from place to place, and serves to inform us, prior to detailed examination of the quadratic fit, which stations have unusual characteristics in these important respects. It is seen that the residual variance or "noise" level differs by an order of magnitude between some pairs of stations. Nevertheless, the majority of stations are clustered together in a fairly compact pattern. The exceptional stations are those in Fennoscandia, where high rates of isostatic uplift are apparently associated with high "noise" levels; and certain stations (Galveston, Manila) which are renowned for the rapid subsidence that has taken place locally in recent decades as the result (it is believed) of human activity (see Pirazzoli, 1986).

Confidence regions for the 1 st and 2nd derivatives of the quadratic regression curve are displayed in fig. 5, the first derivative being estimated at 1987. These plots should immmediately dispel any notion that RSL trends conform to a single model based on 


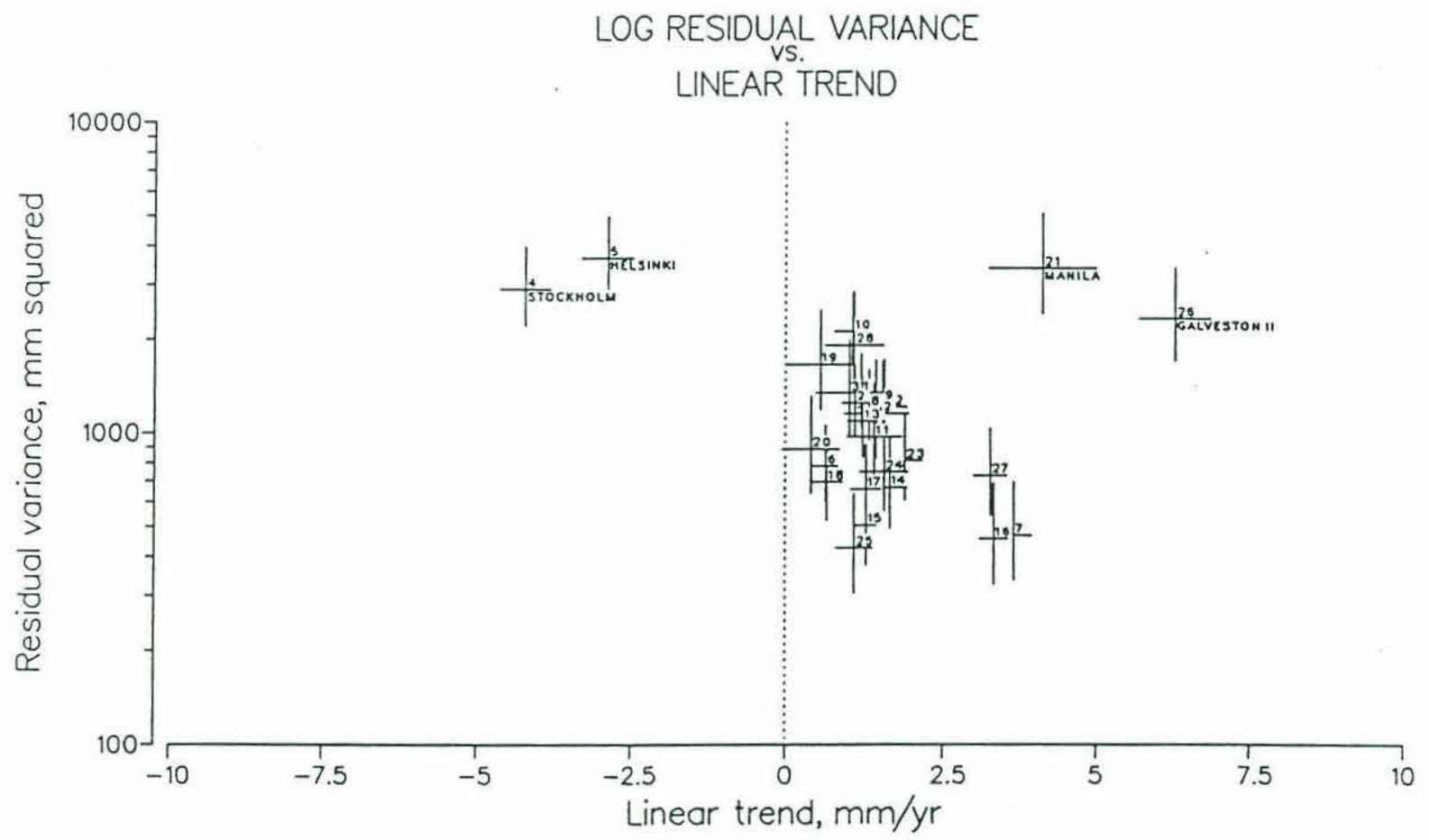

Figure 4: Residual variance $s^{2}$ after quadratic trend removal, and linear trend $b$ from a straight-line fit. 

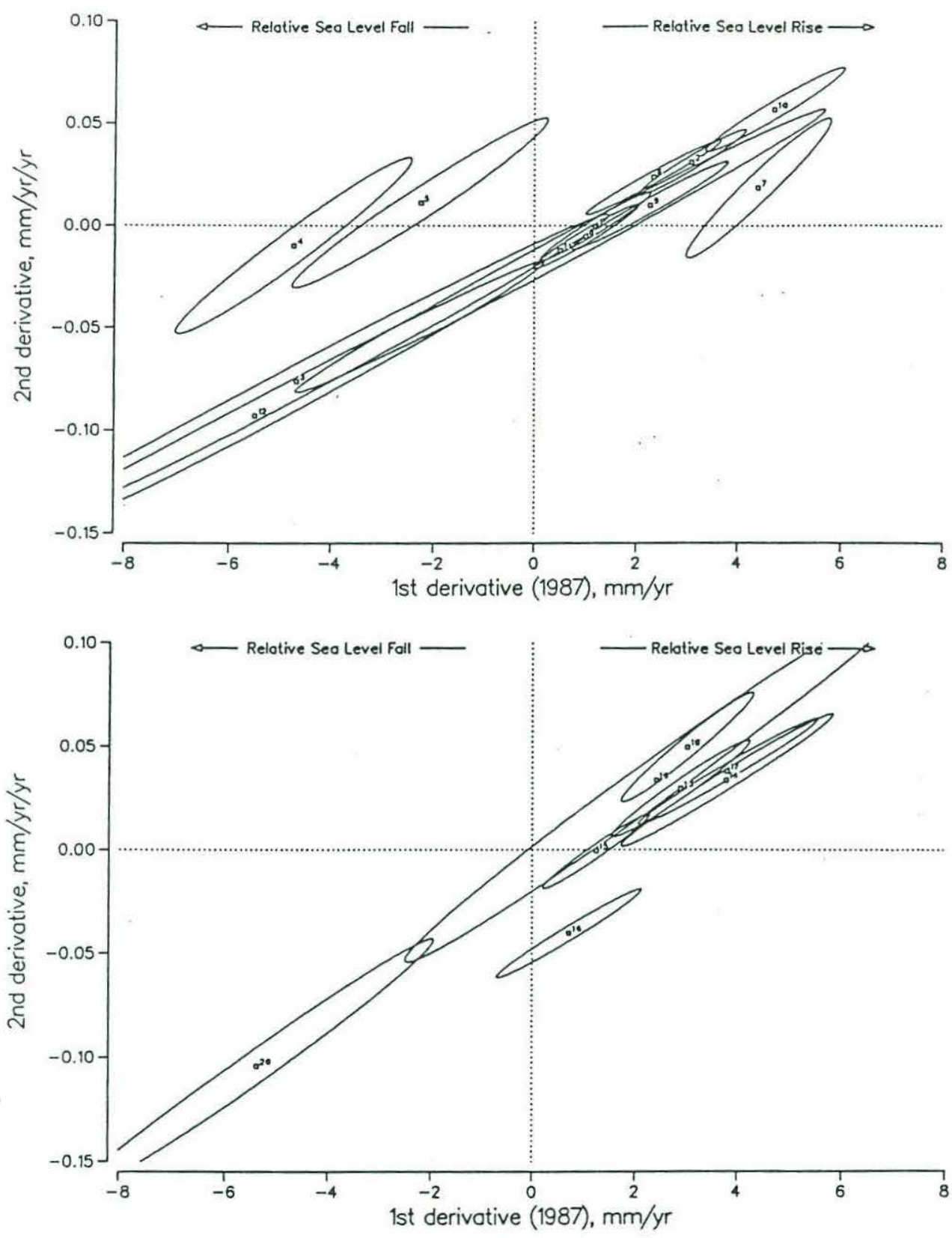

Figure 5: Derivatives of quadratic regression curves through sea-level data at 28 stations, arranged by group as in table 2. (Three of the curves are shown in fig. 3.) Ellipses are contours of equal probability density bounding $95 \%$ confidence regions. Continued on next page. 


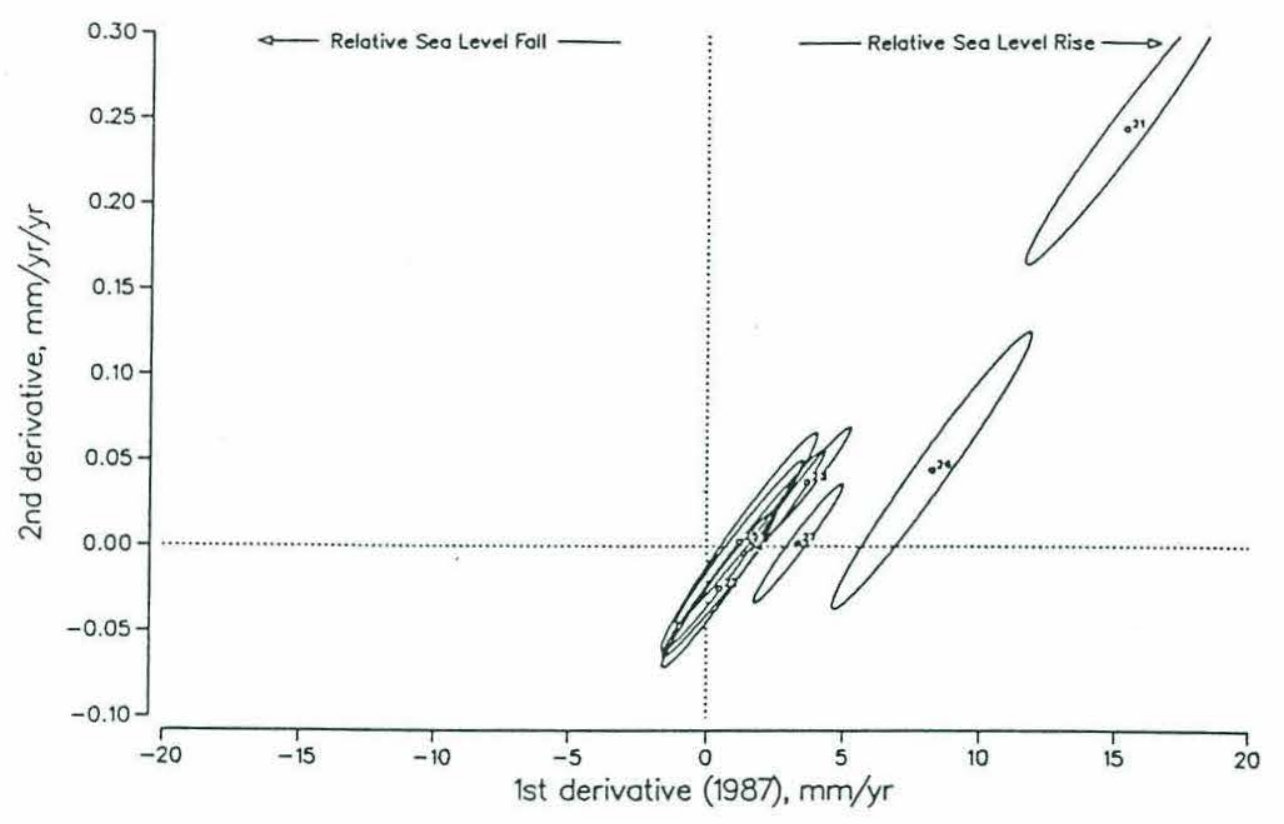

Figure 5: Continued.

"global" parameters. The trends (1st derivatives) are quite distinct and vary over a wide range. It is true that rising $\mathrm{RSL}$ is more common than falling RSL, in agreement with earlier findings. But there is certainly no single trend value that appears within $95 \%$ of the confidence regions. (In fact, confidence limits for the parameter on either axis alone are even smaller than the projections of confidence ellipses onto that axis.) The spread of the trend estimates is as great as the mean value about which they are clustered, confirming that the "sea-level rise" of the last century is largely a regional or local phenomenon - a fact that has long been known but which marine geologists (e.g. Aubrey, 1985; Pirazzoli, 1986) have recently had to emphasize anew in the face of publicity surrounding possible eustatic SL rise. The rates at which RSL trends around the world are increasing (2nd derivatives) are less distinct, but still exhibit statistically significant variations.

The pronounced tilt of the confidence regions in fig. 5 is mainly due to the selection of 1987 as the year for which the first derivative (RSL trend) is given. There is a point near the middle of the time domain for each data series, where the instantaneous value of the first derivative is the same as that given by the linear model and is not affected by errors in estimating the second derivative. At this point ( $\tau=\tau_{0}$, say) the estimates of the derivatives are uncorrelated and their joint confidence region would not have the 
diagonal alignment seen in fig. 5. For $\tau>\tau_{0}$, on the other hand, larger values of the second derivative imply proportionately larger values of the first derivative, and this slants the confidence regions. Each region's slant is controlled by how much $\tau=1987$ differs from $\tau=\tau_{0}$, which depends on the mean value of $t$ and also, according to the second of eqns. (2), on the skewness of the observations in the time domain and on the times at which changes in the reference level (if any) occur. Since the most certain parameter estimates are likely to come from longer series, the smaller confidence regions tend to tilt farthest from the vertical.

An important consequence of the tilt just described is this: the present (e.g., 1987) RSL trend is seriously underestimated by the usual linear regression analysis at those stations where the 2 nd derivative is significantly greater than zero. (The reverse is of course true if the 2 nd derivative is significantly less than zero.) The trend that would be given by linear regression analysis (table 2 ; fig. 4) can be found from fig. 5 by extrapolating a line through the uppermost and lowermost points of each ellipse to its intersection with the horizontal grid axis. In many cases this trend value lies well to one side of the plotted confidence region (ellipse).

For comparison with earlier studies based on averaging techniques, a global mean RSL curve is presented in fig. 6 . The curve in fig. $6 \mathrm{a}$ is an equally weighted average of all available data (from the 28 stations) for each year. Different portions of the curve are therefore subject to the different geographic biases represented in fig. 1. The increase in trend over the last century, as reported by the various investigators already cited, is plainly visible. But is the increase inherent in the individual series being averaged or is it introduced through geographical bias? After removal of the linear trends from all data series, the suspected long-term increase of the RSL trend is found to be absent from the global average (fig. 6b). The "increase" is therefore associated with the linear trends and its appearance in fig. 6a must be a result of geographical bias.

The continuing acquisition of data by nearly all of the tide-gauge stations drawn on in this study offers the prospect of improved confidence in future results, though this can come about only gradually. The possiblity of detecting accelerated RSL trends in the midst of the "noise" obscuring them is enhanced if the trend is strong, the noise weak, or the observation interval long. If a complete record of $T$ annual mean SL observations is available at a station where sea level varies according to the model (3) with $k=1$, the change in trend $2 b_{2} T$ over the entire interval is significantly different from zero at the 

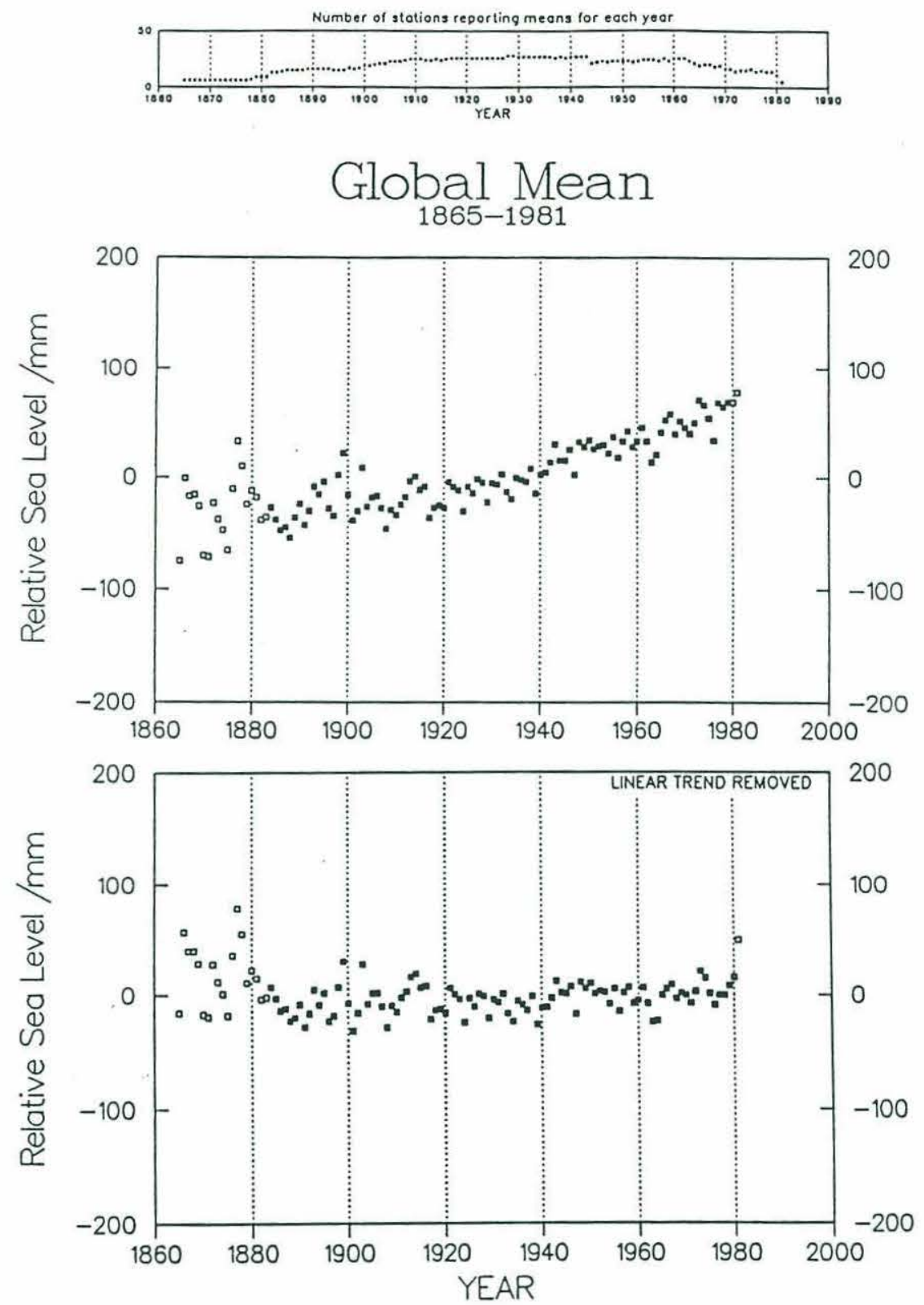

Figure 6: Variation of global mean sea level derived by averaging data from the stations reporting for each year.

(a) data averaged without removing trends.

(b) data averaged after removal of linear trend from each series. 


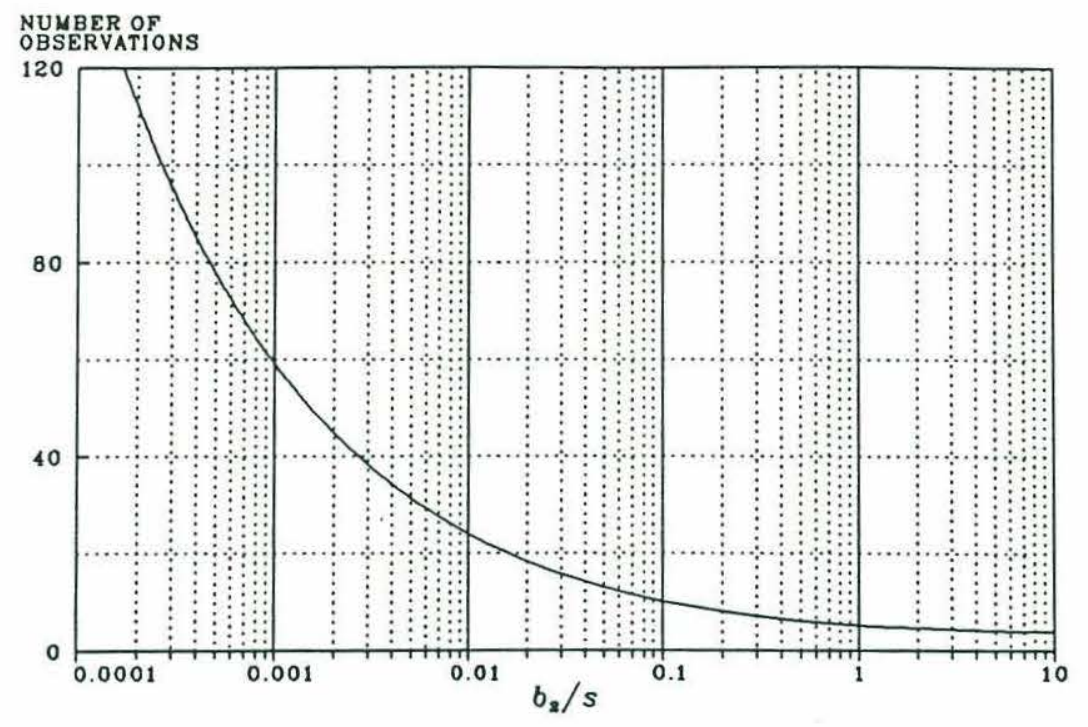

Figure 7: Number of consecutive observations required to render a quadratic trend statistically significant at the $95 \%$ confidence level. The unit on the horizontal axis is the observation interval to the power -2 .

$95 \%$ confidence level only after the number of years plotted in fig. 7 . Taking into account the typical values $20 \mathrm{~mm}<s<50 \mathrm{~mm}$, it can be seen that 60 to 90 years of data are needed to establish even a moderately large 2 nd derivative of magnitude $0.02 \mathrm{~mm} \mathrm{yr}^{-2}$ (a change in trend of $\pm 2 \mathrm{~mm} / \mathrm{yr}$ over a century). Interpretation is even more difficult: the problem of recognizing an accelerated eustatic SL trend based on worldwide tide-gauge data is compounded by the challenge of separating the eustatic contribution from other effects, like accelerated subsidence due to human activities.

The question of whether a higher-order polynomial trend should be incorporated into the model arises, since the truncation after the quadratic term was a subjective decision. But the decision was taken partly because no mechanism has been postulated that would predict or explain the magnitude of a higher-order, long-term trend of a specific analytical form (e.g., cubic); and considering the regional/local character now attached even to the quadratic trend, the selection of suitable prescribed functions to be fitted appears more difficult yet. Furthermore, Barnett (1984) noted that on a time scale of 50 years, removal of the linear trend alone from an average curve left a residual indistinguishable from white noise on the basis of its correlation function. His conclusion was that higher-order fits are likely fictitious. 
More objective analysis techniques are available, however, and several more hopeful observations may be made. First, a resemblance to random noise does not mean that the residual RSL pattern can't be explained - its cause may just be linked with some other noisy geophysical variable. The residuals therefore deserve to be investigated further. Second, the residuals may contain systematic patterns which would be of obvious interest but are masked by a noisy component. It may therefore be worthwhile attempting to remove any part of the "noise" that can be identified. Finally, it has not been assumed that the mechanisms responsible for the quadratic trend make no contribution to the higher-order/shorter-term RSL variability. Such contributions, if any, remain intact in the residual series a and will simply be studied by other methods. With these justifications, attention is turned in the next section to the residual RSL patterns following quadratic trend removal.

\section{Empirical orthogonal function (EOF) analysis}

Methods. Having fitted a quadratic trend to the data, and subsequently removed it, the need to interpret the residual data series in terms of functions whose form is not known in advance demands objective methods of identifying suitable functions. By analogy with the general regression formula (1), we may now seek an expansion of the residual series in the form

$$
a(t)=c_{1} g_{1}(t)+c_{2} g_{2}(t)+\cdots+c_{n} g_{n}(t),
$$

in which the functions $g_{j}(t)$ as well as the coefficients $c_{j}$ are to be determined empirically, and which may subsequently be modified by weighting. Analysis of $m$ data series involves $m$ equations like the one above, which can be written as a matrix equation $\mathbf{A}=\mathbf{C G}$. The columns of $\mathrm{C}$ will be written as $\mathbf{c}_{j}$ and these vectors are, in effect, geographic maps indicating the spatial distribution of each $g_{j}(t)$. Functions $g_{1}, \ldots, g_{n}$ can always be chosen so that a complete expansion of every series $a(t)$ is possible, without $n$ exceeding the number of series; $n$ is minimized if all the functions are independent linear combinations of the different series. In practice, $m$ such combinations are normally required and the coefficient matrix $\mathrm{C}$ is a square $m \times m$ matrix of full rank.

It is desirable that each successive term in the expansion (i.e., each mode $\mathbf{c}_{j} g_{j}(t)$, which is a matrix of the same dimensions as $\mathbf{A}$, but of rank 1) should be optimized to embody as much as possible of the total variabilty (sum of squares) of the data set,

$$
\operatorname{var} A=\Sigma_{i, t} a_{i}^{2}(t)
$$


- or, when $j>1$, of the outstanding part of the data set. This sense of the term "optimal", with reference to the variability or its later modifications, is retained throughout the paper, since the great strength of EOF analysis is its ability to capture much variability in a few modes. (See Aubrey \& Emery, 1986, for further discussion.) In most situations the successive products $\mathrm{c}_{j} g_{j}(t)$ are uniquely determined by the optimization, and the functions $g_{1}, \ldots, g_{n}$ are orthogonal to one another: no cross-cancellation of their variability (sum of squares) is possible. Sets of functions derived from a data set in this way were called "empirical orthogonal functions" by Lorenz (1956). The paired $\mathbf{c}_{j}$ and $g_{j}(t)$ are so far indeterminate by mutually reciprocal scale factors, and we may require $g_{j}(t)$ to be normalized (i.e., to have unit length, $\Sigma_{t} g_{j}^{2}(t)=1$ ) so that $\mathrm{G}$ is a matrix with orthonormal rows (i.e., $\mathrm{GG}^{\dagger}=\mathrm{I}$ ). The total variability $\lambda_{j}$ (sum of squares) of each mode $\mathrm{c}_{j} g_{j}(t)$ is then just $\lambda_{j}=\Sigma_{i} c_{i j}^{2}$. (In matrix terms, $\mathrm{C}^{\dagger} \mathrm{C}$ is a diagonal matrix $\Lambda$ containing the values of $\lambda_{j}$.)

A greater degree of symmetry can be attained by also introducing normalized spatial vectors $\mathbf{e}_{j}=\mathbf{c}_{j} / \lambda_{j}^{1 / 2}$. The unweighted expansion of each $a(t)$ is then

$$
a(t)=e_{1} \lambda_{1}^{1 / 2} g_{1}(t)+e_{2} \lambda_{2}^{1 / 2} g_{2}(t)+\ldots+e_{n} \lambda_{n}^{1 / 2} g_{n}(t),
$$

or in matrix form $\mathbf{A}=\mathbf{E} \boldsymbol{\Lambda}^{1 / 2} \mathbf{G}$. The vectors $\mathbf{e}_{j}$ and functions $g_{j}(t)$ that capture the greatest possible variability in each successive term of the expansion are the eigenvectors of the square matrices $\mathbf{A} \mathbf{A}^{\dagger}$ and $\mathbf{A}^{\dagger} \mathbf{A}$ respectively, ranked according to the eigenvalues $\lambda_{j}$. Because there are fewer stations in this study than years of data, C can be computed more efficiently than $\mathbf{G}$. $\mathbf{G}$ can then be found directly from $\mathbf{A}, \mathbf{C}$, and $\boldsymbol{\Lambda}$, for if $\mathbf{C G}=\mathbf{A}$ and $\mathbf{C}^{\dagger} \mathbf{C}=\boldsymbol{\Lambda}$, then $\mathbf{G}=\boldsymbol{\Lambda}^{-1} \mathbf{C}^{\dagger} \mathbf{A}$. For further details, see Jones (1984).

Issues that have a bearing on the results and on how they should be interpreted include the use of weighting factors and the handling of missing data.

If one desires to assign different weights to different rows or columns of $\mathbf{A}$ (i.e., to different stations or years) in evaluating its "variability" (sum of squares), this is done by defining the weighted variability as the sum of squares of $\mathrm{V}^{-1 / 2} \mathrm{AW}^{-1 / 2}$ where $\mathrm{V}$ and $\mathrm{W}$ are square matrices containing the weighting factors. Provided that $\mathrm{V}$ and $\mathrm{W}$ are diagonal matrices containing elements $v_{i}$ and $w(t)$ respectively, this sets the weighted variability equal to

$$
\sum_{i, t} \frac{a_{i}^{2}(t)}{v_{i} w(t)},=\operatorname{tr}\left(\mathbf{V}^{-1 / 2} \mathbf{A W}^{-1} \mathbf{A}^{\dagger} \mathbf{V}^{-1 / 2}\right) .
$$

By carrying out EOF analysis on the matrix $\mathrm{V}^{-1 / 2} \mathrm{AW}^{-1 / 2}$, an optimization of successive modes in terms of the weighted variability can be achieved. 
A common practice is to choose $\mathbf{V}$ equal to the diagonal part of $\mathbf{A} \mathbf{A}^{\dagger}-$ i.e. $v_{i}=$ $\Sigma_{t} a_{i}^{2}(t)$, which is the variability of the $i$ th series - and $\mathbf{W}$ equal to I (the identity matrix). Then the total weighted variability is the trace of the "correlation matrix" $\mathbf{V}^{-1 / 2} \mathbf{A A}^{\dagger} \mathbf{V}^{-1 / i^{2}}$ which has only 1 's on the diagonal. By applying EOF analysis to the weighted series $\mathrm{V}^{-1 / 2} \mathrm{~A}$, one obtains the expansions $\mathrm{V}^{-1 / 2} \mathrm{~A}=\mathrm{CG}$ and $\mathrm{A}=\mathrm{V}^{1 / 2} \mathrm{CG}$. This reweighted analysis was applied to global tide-gauge data by Barnett (1983). In that paper, however, the method was applied to the original data series without prior trend removal, with the result that a linear trend dominated the first eigenmode (which was the only one displayed).

Reweighted EOF analysis guarantees that all data series are assigned equal overall weights. The effect on the final outcome is to maximize the total (or average) of the percentages of variability accounted for in all data series, by each successive mode rather than the total of the actual variability accounted for. The proportion of the data set's total variability captured in the first mode is necessarily less when it is determined by reweighted EOF analysis than when it is determined by the basic method, which is optimal in this sense. In addition, the emphasis on distributions of "percentage of variability accounted for" makes the reweighted analysis ill-suited for use in conjunction with physical models, which are rarely expressed in terms of such a quantity. (The intent of the re-weighting scheme is normally to bring out weak but pervasive signals in preference to strong, localized signals, without discarding the records that contain the latter. But contamination of the weak signal is better avoided if those records are discarded.) The results of EOF analysis presented in this paper are based on unweighted data sets, which should be borne in mind when comparing the results with other publications.

A routine EOF analysis that makes no provision for the handling of missing data values is inadequate for studying the available sea-level data. Appendix 2 shows how this issue (a problem that is not at all trivial) has been handled, and looks at the prospects for its proper resolution.

Results. EOF analysis was applied to the residual data set (28 series with quadratic trends removed) without re-weighting. Missing data were handled by least-squares approximations to indicated data (see Appendix 2). The results (fig. 8) clearly identify the spatial patterns associated with two temporal functions responsible for the greatest part of the variability. The variability in the first eigenmode ( $31 \%$ of the total) appears to have a nearly stationary random pattern in time, with little correlation from one year to the 

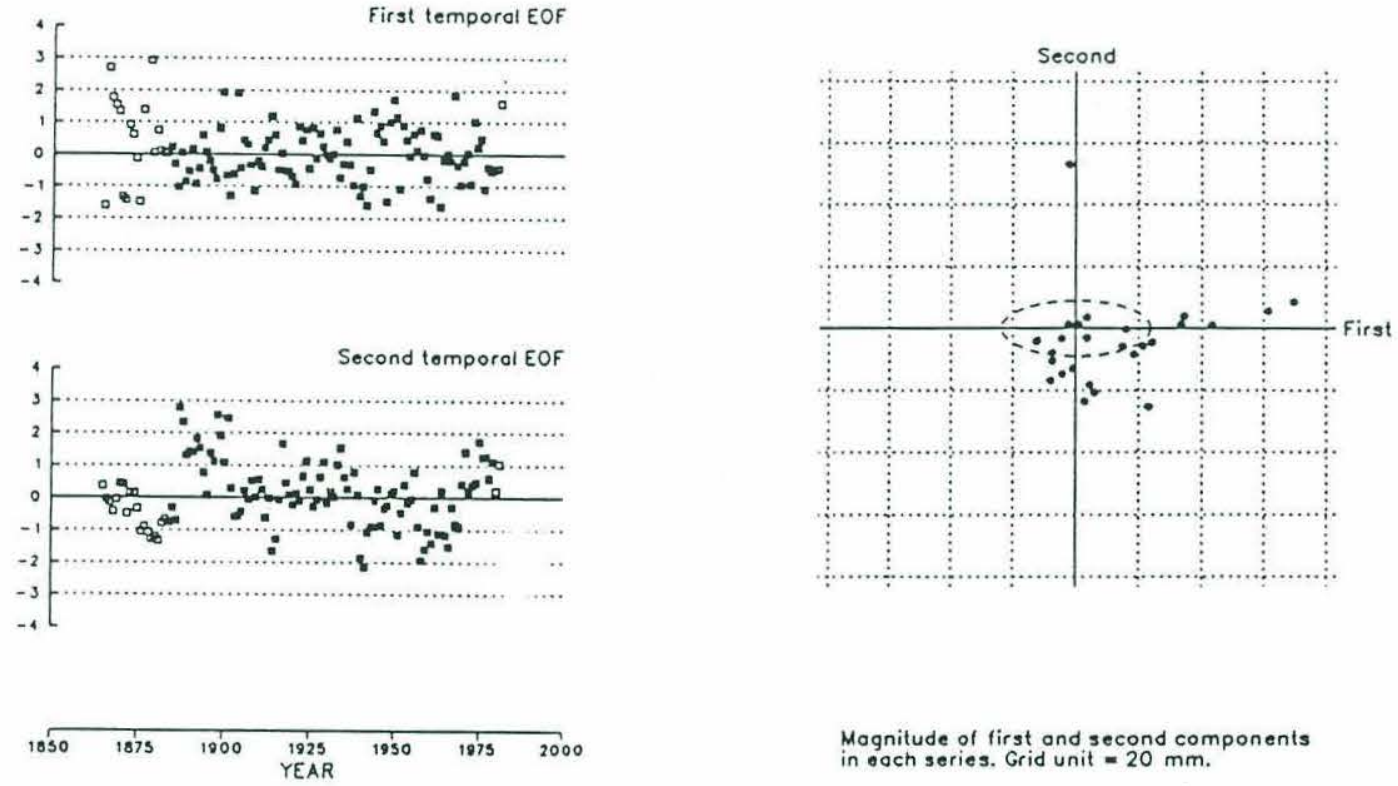

Magnitude of first and second components in eoch series. Grid unit $=20 \mathrm{~mm}$.

Figure 8: Results of EOF analysis: the first two (dominant) temporal functions $\sqrt{N} g_{j}(t)$ and their contribution to each data series, $c_{i j} / \sqrt{N}$. The dashed curve in the diagram on the right is the covariance ellipse, with major axis $\sqrt{\lambda_{1} / m N}$ and minor axis $\sqrt{\lambda_{2} / m N}$. 
next, and is associated with stations in the Baltic Sea, where station density is greatest. The r.m.s. amplitude of the fluctuations in the first mode is 60 to $70 \mathrm{~mm}$ at some of these stations. The Baltic pattern will here be treated as a representative "regional" signature, so that a preliminary comparison of regional and global fluctuations can be made. The 2nd eigemmode ( $14 \%$ of total variability) is associated mainly with a single series, that from Manila. Any global pattern is weak by comparison with these regional and local signatures.

To derive a quantitative upper limit on the magnitude of any global fluctuations requires a definition of sorts. Let us suppose that "global" or "globally coherent" fluctuations are coherent components with the same phase and more or less the same magnitude at all places. All such components will combine with only minor cancellation to produce a single "global" component: if it exists, it is roughly orthogonal to the components shown in fig. 8 , and has less total variability than either of them. The eigenvalue corresponding to this global component must be less than $\lambda_{2}$, so $\sqrt{\lambda_{2}}=10 \mathrm{~mm}$ (see fig. 8 ) is an upper limit on its amplitude (r.m.s. over both space and time). Doubling this value to allow for a reasonable amount of spatial variability consistent with the definition of "global" leads to an upper limit of roughly $20 \mathrm{~mm}$ on the r.m.s. amplitude of the global component at any station. This is a preliminary figure and can undoubtedly be reduced by further analysis. Simple averaging of the 28 residual data series yields a global mean residual with r.m.s. amplitude of about $16 \mathrm{~mm}$ - part of which is probably due to the heavily represented regional pattern in the Baltic, so this too is an upper limit. Global uniformity is a stricter condition than global coherence, so the global mean provides only a crude estimate of the value being sought, but the global mean and upper limit derived from $\lambda_{2}$ are together adequate to show that any "global" fluctuations are at least several times weaker than regionally coherent fluctuations in some parts of the Baltic.

\section{Interpretation}

Relative sea-level variations are due primarily to regional or local phenomena: this has been shown for long-term (50- to 100-year) trends by statistical modelling and for more rapid fluctuations by the dominance of eigenmodes with a regional or local structure. The only "global" feature of the RSL data that is comparable in magnitude is the tendency of long-term trends to be positive, with a spatially and temporally averaged rate of rise between 0.6 and $1.8 \mathrm{~mm}$ per year. Departures from this mean trend are of comparable or 
greater magnitude at most places. The regional and local character of RSL variability has consequences for our understanding of its underlying causes, which will now be examined. We also wish to see whether the spatial patterns that have appeared in this study are in agreement with earlier regional studies that have benefitted from denser spatial sampling.

The idea of a "eustatic" signal should be disposed of first. Unfortunately, the word has had rather a confused history, but one aspect remains unambiguous. From the concept's earliest days, it has been based on the supposition that relative sea-level changes can be separated into two components: land-level changes and ocean-level changes. From Suess (1904/24), who introduced the term "eustasy", to Mörner $(1976,1986)$, who attempted to pin it down with diagrams and careful definitions, proponents of the concept have founded their arguments on this distinction. Ocean-level changes have been placed in three categories:

- "eustatic" changes in the traditional (narrow) sense, resulting from changes in ocean volume and basin geometry,

- "geoidal eustasy" (Mörner, 1976), resulting from changes in the apparent gravitational field of the earth, and

- "dynamic" changes resulting from oceanographic or meteorological effects.

The inclusion of geoidal sea-surface changes under the heading of "eustasy" was a change recommended by Mörner (1976) and since promoted in numerous publications by him. This change was a radical step in geologists' thinking about coastline evolution, meaning that eustatic changes could no longer be considered globally uniform, and it has influenced many other writers. Regrettably Mörner himself (1986) has since urged yet another change, and now says that dynamic changes are to be counted as eustatic also. This renders eustasy synonymous with "ocean level changes" (or "absolute sea-level changes"), which was a perfectly adequate (and more easily understood) term for a concept quite removed from the widely accepted meaning of "eustasy".

The distinction between land-level and ocean-level changes is certainly an appealing one, but it does not lend itself readily to quantification. The global geodetic control needed to measure land-level and ocean-level changes individually is still only a goal albeit a promising one (Carter et al., 1985). Without such measurements, the utility of distinguishing the two components is largely lost, because they do not correspond to two groups of different processes: some processes (such as isostatic readjustment, especially over large regions) are manifest as both land-level changes and changes of basin geometry. 
What we really seek in studies of long-term RSL rise is to understand the contributions made by specific processes. It should now be apparent that some of the terminology commonly encountered is relevant to this aim, and that some (including "eustasy") is less appropriate while only relative and not absolute sea-level data are available. In this paper, RSL change will be considered in terms of the following process-related contributions:

1. ocean volume changes

2. erosion and accretion of the seafloor

3. ocean-basin expansion and contraction (horizontal crustal movements beneath the sea)

4. vertical crustal movements

5. geoidal eustasy

6. dynamic changes.

Items (1), (2), and (3) are all included in the narrow sense of the word "eustasy", and their effect on sea level is globally uniform for all practical purposes, since the apparent gravitational potential gradient at sea level varies with latitude by only 5 parts per thousand. Item (4) leads to both eustatic and land-level changes, and may include a global component but is not globally uniform. Items (5) and (6) entail redistribution of ocean waters over the earth's surface.

Some published estimates of the rates at which these contributions can affect relative sea levels are collected in table 4. The tabulation is by no means exhaustive, but is sufficient to guide our discussion. Certain inferences are well established. The erosion and accretion of the seafloor, and its horizontal movements, have long time scales, and rates that are negligible in the context of this paper. Vertical crustal movements and changes in the volume of ocean water cannot be ignored; their greatest effects are, however, an order of magnitude less now than during the main stages of retreat of the last glaciation. There is disagreement over the likely rate of geoidal changes and a lack of information on the rate of dymamic changes: in both cases the amplitude of the fluctuations, if observed over a sufficiently long interval, would probably be comparable to that of the present-day spatial variability, but the corresponding time scales are unknown.

The predominance of regional and local variability documented by this study implies that vertical crustal movements and/or dynamic changes and/or (possibly) geoidal eustasy 


\begin{tabular}{|c|c|c|c|c|}
\hline CONTRIBUTION & IIME SCALE & BASED OH & RATE & 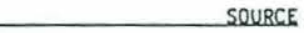 \\
\hline \multicolumn{5}{|l|}{ Ocean volume change } \\
\hline \multirow[t]{3}{*}{ - net influx } & $7000 \mathrm{yr}$ & volime of former fce sheets & $10 \mathrm{~mm} / \mathrm{yr}$ & Donovan \& Jones, 1979 \\
\hline & $75 \mathrm{yr}$ & global water budget 1900-1975 & $1.5 \mathrm{~mm} / \mathrm{yr}$ & Klige, 1982 \\
\hline & $75 \mathrm{yr}$ & global water budget 1900-1975 & $0.5 \mathrm{~m} / \mathrm{yr}$ & Robin, 1986 \\
\hline - thermal expansion & $50 \mathrm{yr}$ & atmosphertc warming $1890-1940$ & $0.5 \mathrm{~mm} / \mathrm{yr}$ & "Etkins \& Epstein, 1982 \\
\hline \multicolumn{5}{|l|}{ Erosion and accretion } \\
\hline - sediment infili & $\begin{array}{l}\text { (years to } \\
\text { decades) }\end{array}$ & $\begin{array}{l}\text { sediment yield of major rivers } \\
\text { (19th and } 20 \text { th centuries) }\end{array}$ & $0.02 \mathrm{~mm} / \mathrm{yr}$ & Gornitz \& Lebedeff, 1982 \\
\hline - vulcanism & (Myr) & plate traversing a hotspot & $0.0002 \mathrm{~mm} / \mathrm{yr}$ & P1tman, 1978 \\
\hline Ocean-basin expansion & $($ Myr $)$ & uplift of Himalayas & $0.002 \mathrm{~mm} / \mathrm{yr}$ & P1tman, 1978 \\
\hline Vertical crustal movements & $2000 \mathrm{yr}$ & Laurentide uplift (early Holocene) & 70 to $100 \mathrm{~mm} / \mathrm{yr}$ & Nikonov, 1980 \\
\hline \multirow[t]{2}{*}{ Geoldal eustasy } & $10^{7} \mathrm{yr}$ & & $0.01 \mathrm{~mm} / \mathrm{yr}$ & Kaula, 1980 \\
\hline & $?$ & & 10 to $30 \mathrm{~mm} / \mathrm{yr}$ & Mörner, 1986 \\
\hline \multicolumn{5}{|l|}{ Dynamic changes } \\
\hline - barometric & $?$ & & $?$ & \\
\hline - geostrophic & $?$ & & $?$ & \\
\hline
\end{tabular}

Table 4: Estimates of possible contributions to the rate of RSL rise on a variety of time scales. Most of the figures quoted are intended as order-of-magnitude estimates only, and some are upper limits. The time scales shown provide a useful sample but do not rule out activity on very different time scales. Annual and high-frequency effects were not included. 
contribute more to deviations from the prevailing (60- to 120 -year) RSL trends than do changes of ocean volume, which would be global in scale. The prevailing trends themselves are in many places influenced more by some combination of those same three agents than by ocean-volume changes, but the global mean trend of order of magnitude $1 \mathrm{~mm} / \mathrm{yr}$ could be partly or entirely due to increasing ocean volume.

\section{Status of work and future directions}

Mention is made here of some aspects of the present investigation that remain incompletely explored but could be taken up immediately. Broader perspectives of the status and goals of RSL research are provided by Aubrey (1985) and IAPSO (1985).

Assessments of relative sea-level change on the time scales considered here are hindered by the lack of data, its uneven geographic distribution, and in some cases its quality. The geographic bias of the early measurements cannot be eliminated; even weighting schemes like that of Gornitz et al. (1982) and Gornitz \& Lebedeff (1987) only partially alleviate the problem. It may be possible to do more concerning the quantity of the data, since several suggestions can be made that remain largely untried. One is to combine data from the PSMSL's current holdings with data from their earlier publications, at those stations for which annual means before 1960 were computed without monthly means. Another is to make use of data not distributed by PSMSL at all. Lastly, overlapping records from closely adjacent stations can be averaged to obtain a single record with a longer time span. These suggestions vary in their acceptability and require further justification before being put into practice. The mathematical theory that has been described includes provisions for the "splicing" of broken data series that might otherwise be considered unusable, and could also be used to improve the data coverage. Inspection of records on the collection of the data is needed in deciding just how reliable a data series is, if the presence of breaks is suspected.

Although this study finds the "global" sea-level trend to be no more important than regional and local variations, and presents no evidence that it departs from a linear trend, gradual changes in that trend cannot yet be ruled out, and computation of confidence intervals for both the first and second derivatives is certainly desirable. Identifying such aspects of "global" sea-level behaviour belongs to a category of statistical problems requiring what can be called "two-stage" analysis. The first stage has been carried out rigorously, leading to confidence intervals, etc., for the trends at individual stations. These confidence 
regions allowed the second stage of analysis - comparison of the trends - to be carried out informally when the results are displayed in suitable visual form, but a rigorous second stage of analysis would encourage faith in the results. Such analysis is hindered by the fact that parameter estimates from different locations have distributions (4) of different variance and shape, so the boundaries of their joint confidence regions are neither identical nor strictly elliptical. The use of a random-effects model to study the global trend seems a natural next step in the investigation (see p. 24).

Mathematical techniques capable of revealing the effect of missing data in eigenanalysis procedures, and procedures that minimize those effects in clearly defined ways, would aid in the interpretation of deviations from long-term RSL trends. This issue is treated in appendix 2. The regression and eigenanalysis procedures that have been described might profitably be employed in regional and local studies. There are interesting possibilities in the application of geophysical data to regional and local tide-gauge studies (Aubrey, 1985), and may also be new ways of using tide-gauge observations (like the association of high "noise" levels with isostatic uplift that was inconclusively pointed out on p. 24) in understanding geophysical phenomena.

\section{Conclusions}

1. Average rates of relative sea-level rise over the 60 - to 100 -year time intervals spanned by many of the longest continuing tide-gauge records show significant regional and local variations that are at least as important as the globally averaged rates ( 0.6 to $1.8 \mathrm{~mm}$ per year) that have often been reported.

2. The rate of sea-level rise is changing at statistically significant rates at many locations. Joint confidence regions for the rate of rise and its rate of change can be plotted using quadratic regression analysis (fig. 5). At places where the rate of rise is changing relatively quickly, the present rate of rise is misrepresented by ordinary linear regression analysis. No evidence is found for a global acceleration of sea-level rise: the changing geographical distribution of data can lead to the false appearance of this phenomenon in averaged sea-level curves.

3. Modifications of the usual regression analysis procedures allow statistical parameters for an entire data series to be estimated even when parts of the series are referred to distinct reference levels (gauge zeroes) separated by an unknown difference. The confidence regions, bands, etc., thus obtained make automatic allowance for the 
unknown when its existence is recognized. Such techniques could be used to expand the usual tide-gauge data base once the causes of suspected changes of reference level have been investigated to the extent possible using historical records.

4. Deviations of mean sea level from quadratic trends are, like the trends themselves, chiefly regional or local phenomena. Eigenanalysis of the 28 data series studied here shows more of the total variability to be associated with a coherent pattern involving 5 records from the region of highest station density (the Baltic Sea) than with any other coherent spatial pattern. Furthermore, a pattern dominated by a single station (Manila) shows more variability than the total coherent pattern for any combination of stations but those in the Baltic. The r.m.s. amplitude of the regional pattern in the Baltic reaches at least $70 \mathrm{~mm}$, that of the global pattern (if any) probably less than $20 \mathrm{~mm}$.

5. Missing data pose a particular problem in RSL studies, but can be handled adequately by least-squares approximations to indicated data, a method described in appendix 2 , which offers a number of advantages over some alternative methods. 


\section{Appendix 1. Numerical example}

To assist the reader in following the matrix notation employed in this paper, a simple numerical example is provided. Consider the sequence of 5 observations $y(t)=$ $(7,1,22,15,30)$ for $t=(1,2,3,4,5)$. If the observations are measured relative to a common datum (so $k=1$ ), then

$$
\begin{aligned}
& N=5 \\
& \mathrm{y}=\left[\begin{array}{lllll}
7 & 1 & 22 & 15 & 30
\end{array}\right] \\
& \bar{y}=\frac{\Sigma y}{N}=\frac{75}{5}=15 \\
& \tilde{\mathbf{y}}=\left[\begin{array}{lllll}
-8 & -14 & 7 & 0 & 15
\end{array}\right] \\
& \tilde{\mathbf{x}}=\left[\begin{array}{lllll}
-2 & -1 & 0 & 1 & 2
\end{array}\right] \\
& b=\frac{\Sigma \tilde{x} \tilde{y}}{\Sigma \tilde{x}^{2}}=\frac{60}{10}=6 \\
& \mathbf{F}=\left[\begin{array}{rrrrr}
1 & 1 & 1 & 1 & 1 \\
-2 & -1 & 0 & 1 & 2 \\
4 & 1 & 0 & 1 & 4
\end{array}\right] \\
& \mathrm{FF}^{\dagger}=\left[\begin{array}{ccc}
5 & 0 & 10 \\
0 & 10 & 0 \\
10 & 0 & 34
\end{array}\right] \\
& \overline{\mathrm{y}} \mathrm{F}^{\dagger}=\left[\begin{array}{lll}
0 & 60 & 14
\end{array}\right] \\
& b_{2}=\frac{(10)(14)-(0)(60)}{(10)\left(34-10^{2} / 5\right)-(0)^{2}}=1 \\
& b_{1}=\frac{60}{10}-(1) \frac{0}{10}=6 \\
& b_{0}=-(1) \frac{10}{5}=-2 \\
& \mathbf{b F}=\left[\begin{array}{lll}
-2 & 6 & 1
\end{array}\right]\left[\begin{array}{rrrrr}
1 & 1 & 1 & 1 & 1 \\
-2 & -1 & 0 & 1 & 2 \\
4 & 1 & 0 & 1 & 4
\end{array}\right]=\left[\begin{array}{lllll}
-10 & -7 & -2 & 5 & 14
\end{array}\right]
\end{aligned}
$$

The analysis-of-variance table is presented as table 5 . 
Quadratic trend $\beta \mathrm{F}\left[\begin{array}{lllll}-10 & -7 & -2 & 5 & 14\end{array}\right] \quad 6 \Sigma \bar{x} \bar{y}+1 \Sigma \bar{x}^{2} \bar{y}=374 \quad 2$

Residual $\alpha$

$\left[\begin{array}{lllll}2 & -7 & 9 & -5 & 1\end{array}\right]$

$\begin{array}{ll}60 & 2 \\ 34 & 4\end{array}$

Table 5: Analysis of variance: numerical example $\overline{\mathbf{y}}=\left[\begin{array}{lllllll}-8 & -14 & 7 & 0 & 15\end{array}\right]$ D.O.F. $=$ degrees of freedom. 
If, on the other hand, the first 2 observations $(7,1)$ had been measured relative to a different datum than the 3 observations $(22,15,30)$, and the difference had not been known, we would have set $k=2$ and subtracted mean values from each subset separately. In this case we would have had

$$
\tilde{y}=\left[\begin{array}{lllll}
3 & -3 & 14 \frac{2}{3} & -7 \frac{1}{3} & 22 \frac{2}{3}
\end{array}\right]
$$

and $\mathrm{F}$ would have been

$$
\left[\begin{array}{rrrrr}
1 & 1 & 0 & 0 & 0 \\
0 & 0 & 1 & 1 & 1 \\
-2 & -1 & 0 & 1 & 2 \\
4 & 1 & 0 & 1 & 4
\end{array}\right] .
$$

Now suppose that two residuals,

$$
\mathrm{a}_{1}=\left[\begin{array}{lllll}
2 & -7 & 9 & -5 & 1
\end{array}\right] \text { and } \mathbf{a}_{2}=\left[\begin{array}{lllll}
1 & -5 & 9 & -7 & 2
\end{array}\right] \text {, }
$$

are to be compared using EOF analysis. The various ways of writing the decomposition,

$$
\begin{aligned}
\mathbf{A} & =\Sigma_{j} \mathbf{c}_{j} g_{j}(t) \\
& =\mathbf{C G} \\
& =\mathbf{E} \Lambda^{1 / 2} \mathbf{G},
\end{aligned}
$$

are illustrated by the example

$$
\begin{aligned}
& {\left[\begin{array}{rrrrr}
2 & -7 & 9 & -5 & 1 \\
1 & -5 & 9 & -7 & 2
\end{array}\right]=\left[\begin{array}{rrrrr}
1.5 & -6 & 9 & -6 & 1.5 \\
1.5 & -6 & 9 & -6 & 1.5
\end{array}\right]+\left[\begin{array}{rrrrr}
.5 & -1 & 0 & 1 & -.5 \\
-.5 & 1 & 0 & -1 & .5
\end{array}\right]} \\
& =\left[\begin{array}{rr}
\sqrt{ } \frac{315}{2} & -\sqrt{ } \frac{5}{2} \\
\sqrt{ } \frac{315}{2} & \sqrt{ } \frac{5}{2}
\end{array}\right]\left[\begin{array}{ccccc}
\frac{1}{\sqrt{70}} & \frac{-4}{\sqrt{70}} & \frac{6}{\sqrt{70}} & \frac{-4}{\sqrt{70}} & \frac{1}{\sqrt{70}} \\
\frac{-1}{\sqrt{10}} & \frac{2}{\sqrt{10}} & 0 & \frac{-2}{\sqrt{10}} & \frac{1}{\sqrt{10}}
\end{array}\right] \\
& =\left[\begin{array}{cc}
\frac{1}{\sqrt{2}} & \frac{-1}{\sqrt{2}} \\
\frac{1}{\sqrt{2}} & \frac{1}{\sqrt{2}}
\end{array}\right]\left[\begin{array}{cc}
\sqrt{315} & 0 \\
0 & \sqrt{5}
\end{array}\right]\left[\begin{array}{ccccc}
\frac{1}{\sqrt{70}} & \frac{-4}{\sqrt{70}} & \frac{6}{\sqrt{70}} & \frac{-4}{\sqrt{70}} & \frac{1}{\sqrt{70}} \\
\frac{-1}{\sqrt{10}} & \frac{2}{\sqrt{10}} & 0 & \frac{-2}{\sqrt{10}} & \frac{1}{\sqrt{10}}
\end{array}\right] \text {, }
\end{aligned}
$$

in which the two modes capture $\lambda_{1}=315$ and $\lambda_{2}=5$ units of variability respectively. (The first mode is here found to be an excellent approximation to $\mathbf{A}$.) 


\section{Appendix 2. Remarks on EOF analysis of incomplete data sets}

An important problem in the study of tide-gauge data is the preponderance of missing data - including particularly data from early years before many of the tide gauges under consideration had been installed. Like the averaging of curves, the computation of EOF's requires full matrices in order to succeed completely. The validity of any "average" sealevel curves or eigenanalysis results rests on the manner in which the missing-data problem is handled. When data series are simply averaged to arrive at a global curve, the missing data for any particular year may be ignored, and the extent to which different parts of the curve show different geographical biases can be inferred directly from the spatial distribution of data for each year. In the case of eigenanalysis, however, the introduction of bias is largely obscured by the abstraction of the method. Standard EOF analysis techniques do not allow the missing values to be ignored, since the computation involves the entire data matrix at once instead of proceeding row by row or column by column; the bias is consequently more than just geographical. Only by restricting attention to the small number of stations with nearly complete records (Barnett, 1983) can this bias largely be eliminated, so there is a need for eigenanalysis algorithms that indicate clearly both the prior assumptions made with regard to missing values and the precise nature of the resulting bias.

In considering this problem, let us return to the residual matrix $\mathbf{A}$ used as an example previously, and let us suppose that two of the values are missing; we might write

$$
\mathbf{A}=\left[\begin{array}{rrrrr}
2 & -7 & 9 & -5 & 1 \\
0 & & 8 & -8 &
\end{array}\right] .
$$

Since ordinary matrix algebra requires that all elements of a matrix be defined, however, we shall suppose that zeroes have been assigned to the blank spaces. The fact that they do not represent actual observations will be signalled by a data indication matrix $\mathrm{D}$ whose elements $d_{i}(t)$ consist only of the digits 0 and 1 :

$$
\mathbf{D}=\left[\begin{array}{lllll}
1 & 1 & 1 & 1 & 1 \\
1 & 0 & 1 & 1 & 0
\end{array}\right]
$$

How should the empirical orthogonal functions be determined? Unmodified EOF analysis of the matrix $\mathbf{A}$ would yield a decomposition $\mathbf{A}=\mathbf{A}_{1}+\mathbf{A}_{2}$ as follows:

$$
\left[\begin{array}{ccccc}
2 & -7 & 9 & -5 & 1 \\
0 & 0 & 8 & -8 & 0
\end{array}\right]=\left[\begin{array}{rrrrr}
1.14 & -3.99 & 9.10 & -6.81 & 0.57 \\
0.99 & -3.46 & 7.89 & -5.91 & 0.49
\end{array}\right]+\left[\begin{array}{rrrrr}
0.86 & -3.01 & -0.10 & 1.81 & 0.43 \\
-0.99 & 3.46 & 0.11 & -2.09 & -0.49
\end{array}\right] \text {, }
$$


which is optimal only under the unnecessary constraint that $a_{i}(t)=0$ if $d_{i}(t)=0$, and furthermore, fails to recognize that the total variability of the data set would inevitably be greater if the missing values had been measured (unless, of course, both measurements really did turn out to be 0 !). By removing the constraint on the missing values of $a_{i}(t)$, it is possible to find alternative decompositions $\mathbf{A}^{\prime}=\mathbf{A}^{\prime}{ }_{1}+\mathbf{A}^{\prime}{ }_{2}$ in which $\mathbf{A}^{\prime}{ }_{1}$ gives a better fit in the least-squares sense to the known part of $\mathbf{A}^{\prime}$. It can be revealed in advance that the decomposition

$$
\left[\begin{array}{rrrrr}
2 & -7 & 9 & -5 & 1 \\
0 & -7.59 & 8 & -8 & 1.08
\end{array}\right]=\left[\begin{array}{rrrrr}
0.92 & -7.00 & 8.13 & -6.29 & 1.00 \\
1.00 & -7.59 & 8.81 & -6.81 & 1.08
\end{array}\right]+\left[\begin{array}{rrrrr}
1.08 & 0.00 & 0.87 & 1.29 & 0.00 \\
-1.00 & 0.00 & -0.81 & -1.19 & 0.00
\end{array}\right]
$$

gives the best such fit in that this choice of $\mathbf{A}^{\prime}{ }_{1}$ minimizes the outstanding variability

$$
\operatorname{var}_{\mathbf{D}}\left(\mathbf{A}-\mathbf{A}_{1}^{\prime}\right) \equiv \Sigma_{i, t}\left[a_{i}(t)-a_{i 1}^{\prime}(t)\right]^{2} d_{i}^{2}(t)
$$

indicated by $\mathbf{D}$. A quick computation is sufficient to show that $\operatorname{var}_{\mathbf{D}}\left(\mathbf{A}-\mathbf{A}^{\prime}{ }_{1}\right)=6.66$ whereas $\operatorname{var}_{\mathbf{D}}\left(\mathbf{A}-\mathbf{A}_{1}\right)=18.63$.

(Given the matrix $\mathbf{D}$, it is tempting to refer to $\mathbf{A}^{\prime}{ }_{1}$ or $\mathbf{A}^{\prime}{ }_{2}$ as having captured a certain percentage of the indicated variability of $\mathbf{A}$ or $\mathbf{A}^{\prime}$. In some situations this is inadvisable, however, because the orthogonality conditions that ensure $\mathbf{A}^{\prime}{ }_{1}$ and $\mathbf{A}^{\prime}{ }_{2}$ will contribute independently to the total variability may not apply to the subsets indicated by $\mathrm{D}$. The result is that in (7), for example,

$$
\operatorname{var}_{\mathbf{D}} \mathbf{A}_{1}+\operatorname{var}_{\mathbf{D}} \mathbf{A}_{2} \neq \operatorname{var}_{\mathbf{D}} \mathbf{A}
$$

even though $\mathbf{A}_{1}+\mathbf{A}_{2}=\mathbf{A}$ and $\operatorname{var} \mathbf{A}_{1}+\operatorname{var} \mathbf{A}_{2}=\operatorname{var} \mathbf{A}$.)

The purpose of this section is to seek modifications of the standard EOF analysis techniques that yield decompositions $\mathbf{A}^{\prime}=\mathbf{A}_{1}{ }_{1}+\mathbf{A}^{\prime}{ }_{2}$ that are preferably optimal like the one given above, or, if not, that are at least improvements on the basic result $\mathbf{A}=\mathbf{A}_{1}+\mathbf{A}_{2}$.

Little \& Rubin (1987) describe 4 broad categories of analysis procedures for incomplete data sets; they involve

1. discarding of incomplete records,

2. imputation (filling in of missing values to permit analysis by standard methods),

3. modification of design weights to adjust for missing values, and

4. basing of inferences on the likelihood under a chosen model. 
It will be helpful to consider the ideas developed now in the context of their list. The first option - analyzing complete records only - is not a realistic alternative in tide-gauge studies, although efforts are usually made to avoid the use of very incomplete records. Options 2 and 3 have been employed in various guises in other papers, because they can be implemented efficiently using existing eigenanalysis routines. Here, though, it will be argued by means of a comparison that the most desirable options lie among the range of possiblities encompassed by the 4th category: model-based procedures. The way is clear for the development of model-based EOF algorithms dedicated to characterizing incomplete data sets, and their application to sea-level studies and to other fields of research can be expected before long.

I wish to consider several possible approaches to the problem of missing data in tidegauge records, including those tried previously by others, and to look at their strengths and shortcomings. To help in assessing the value of each approach, let us first list some of the desirable properties sought in the results:

(i) successive modes should approximate the outstanding part of the data set as closely as possible.

(ii) The total number of modes should be minimized: in particular, it should not exceed the smaller dimension of the matrix.

(iii) Summation of all modes should reconstruct the known part of the data set.

(iv) Any pair of modes should satisfy an orthogonality condition (allowing statements about the percentage of variability captured by each mode).

(v) The results should be interpretable as estimates of statistical model parameters, with desirable properties (e.g. maximum likelihood).

As we have already seen, the orthogonality condition mentioned in (iv), if it refers to the observed part of the data, must differ from the remarkably strong orthogonality conditions associated with standard eigenanalysis results. Condition (v) is even harder to satisfy: it requires a fully developed theory in Little \& Rubin's 4th category. Neither problem is insurmountable, however, so let us proceed to survey the existing methods and try to take a step in the desired direction.

IMPUTATION. Because they can be implemented with great ease, a variety of imputation methods are in common use. It was by filling missing values in with zeroes 
that the basic decomposition $\mathbf{A}=\mathbf{A}_{1}+\mathbf{A}_{2}$ obtained earlier in this section. Barnett (1983) used interpolation and extrapolation to complete his data set. A sum over all eigenmodes is guaranteed to reproduce the entire data set, but in general, imputed values (other than zeroes) tend to reflect an investigator's preconceived notions of what the missing data should look like, and may either improve or diminish the ability of the first few modes to approximate the known part of a data set. Rarely if ever is any attempt made to assess these effects. And although strong orthogonality conditions apply to the result, they are based on the variability of the filled-in matrix, which typically underestimates that of the complete data set. Imputation is therefore not recommended unless the missing data constitute only a very small portion of the data set.

EIGENVECTOR-WEIGHTED AVERAGING. In this method, used by Barnett (1984), the spatial covariance or correlation matrix for the completed data set is estimated by computing the covariance of each pair of records over the time domain for which both records contain measurements. The first spatial eigenvector is then computed and its like-signed components are used as weights in calculating an average of the different data series. The method bears a superficial resemblance to principal component analysis to the extent that a curve proportional to the first principal component would be obtained if the available data set were complete and all stations were in phase with respect to this component. Neither condition is met in the data set employed here, however. A more fundamental criticism when the method is considered in its original context is that the weighting scheme chosen cannot be said to yield a credible "average" trend because if the first principal component is a linear trend, the components of the first eigenvector are themselves proportional to the magnitude of the trend. To calculate an average using weight factors that are proportional to the quantity being averaged assures a result that is too high. This discredits Barnett's (1984) "overall average" trends (see table 1). The main point to be made about Barnett's method in the context of this appendix, however, is that it is genuinely an averaging scheme, yields only one mode of variability, and is too far removed from eigenanalysis to be very helpful in constructing the expansion (6).

\section{SPARSE EIGENANALYSIS OF AUBREY \& EMERY (1986).}

Modifications of the usual EOF-analysis procedures to allow for missing data were proposed by Aubrey \& Emery (1986) in a study of Japanese tide-gauge records. 
First, they adjust each data series by adding a constant so that its linear trend (which has not been removed) would have zero mean if averaged over the entire time domain of the analysis. Then the product $\mathbf{A A}^{\dagger}$ is formed from the matrix A (with filled-in zeroes, following the notational convention of this appendix) and each sum involved in the calculation is, in effect, weighted or scaled to make up for the terms that are lacking. If only 4 out of $N$ terms are available when a sum is to be evaluated, for example, the 4 terms are added and the result multiplied by $N / 4$. Thus the average of the available terms is used as an estimate of the average of the unavailable terms. If use of a weighting matrix $\mathbf{V}$ is desired (see text), the diagonal part of the modified $\mathbf{A} \mathbf{A}^{\dagger}$ is used. After the matrix of spatial eigenvectors, $\mathbf{E}$, is obtained from the modified $\mathbf{A} \mathbf{A}^{\dagger}$, the temporal functions are found from $\mathbf{E} \boldsymbol{\Lambda}^{1 / 2} \mathrm{G}=\mathrm{AW}^{-1 / 2}$ or $\mathbf{E} \boldsymbol{\Lambda}^{1 / 2} \mathbf{G}=\mathbf{V}^{-1 / 2} \mathbf{A W}^{-1 / 2}$ as appropriate, in which $\mathrm{W}$ is a diagonal matrix consisting of elements $w(t)=\frac{1}{m} \Sigma_{i} d_{i}(t)$.

The linear trend compensation step need not be considered here because in this paper EOF analysis is applied only after trend removal. The remaining steps fall into Little \& Rubin's 3rd category of procedures (weighting schemes) and have the advantage of following closely the approach used for complete data sets (yielding identical results when applied to a data set that actually is complete). There would be additional difficulties in interpreting the results if the method were employed here, however. The weighting scheme used to modify $\mathbf{A A}^{\dagger}$ has some appeal as long as the presence or absence of data is thought to be uncorrelated with the observations themselves. But when contiguous segments of data are missing from a record suspected of showing long-term variability, especially from the beginning or end of the record, this notion is not easily sustained. Because such circumstances are particularly relevant to the present study, the method is thought less suitable for use here than one which emphasizes the fitting of functions to the known part of the data set only. Such a method will be described shortly. Two other disadvantages of the modified $\mathbf{A A}^{\dagger}$ just mentioned are that the conditions imposed on the missing data are not made explicit, and that data from relatively incomplete series are weighted more heavily than data from series that are nearly complete. These issues will also be addressed.

The method of Aubrey \& Emery (1986) will be applied to the example laid out earlier before some alternative methods are discussed. Without the linear-trend 
compensation step, it yields the following "pseudo-decomposition" of the matrix A:

$\left[\begin{array}{ccccc}2 & -9.90 & 9 & -5 & 1.41 \\ 0 & 0 & 8 & -8 & 0\end{array}\right]=\left[\begin{array}{lllll}.86 & -4.25 & 7.82 & -6.11 & .61 \\ .99 & -4.90 & 9.02 & -7.04 & .70\end{array}\right]+\left[\begin{array}{rrrrr}1.14 & -5.65 & 1.18 & 1.11 & .81 \\ -.99 & 4.90 & -1.02 & -.96 & -.70\end{array}\right]$,

with $\operatorname{var}_{\mathbf{D}}\left(\mathbf{A}-\mathbf{A}^{\prime}{ }_{1}\right)=14.58$. Thus the first term provides a better approximation to $\mathbf{A}$ than the basic result $\mathbf{A}_{1}$ presented at the beginning of the section (eq. 7 ), but is not as good as the optimal solution in eq. (8). Lack of orthogonality and failure to duplicate two of the known elements of $\mathbf{A}$ are evident too in this example.

\section{LEAST-SQUARES APPROXIMATIONS TO INDICATED DATA.}

During the course of this study, a search for EOF-analysis methods capable of handling missing data, while satisfying as many of the desired conditions (i) to (v) as possible, led to the idea of identifying and removing successive least-squares approximations to the available data with the help of an iterative technique.

To permit a proof of one particularly important feature, let us introduce some formal definitions before explaining the method:

An indication matrix is a matrix $\mathrm{D}$ whose entries $d_{i l}$ consist only of 0 's and 1's.

The domain indicated by an indication matrix $\mathrm{D}$ (or more briefly, the indicated domain) is the set of index combinations $(i, l)$ such that $d_{i l}=$ 1.

The complementary domain is the set of index combinations $(i, l)$ such that $d_{i l}=0$.

Now, let us consider an arbitrary data matrix $\mathbf{A}$ with the positions of known data indicated by an indication matrix $\mathrm{D}$. To approximate the entries of a matrix $a_{i l}$ by products $c_{i} g_{l}$ as closely as possible over the indicated domain, according to the leastsquares criterion, we may minimize the residual variability $\Sigma_{i l}\left(a_{i l}-c_{i} g_{l}\right)^{2}$ subject to the constraint that the residual variability over the complementary domain (the complementary variability be held constant. It is undesirable to fix any of the products $c_{i} g_{l}$ in advance, however, because we wish to obtain both $\mathrm{c}$ and $\mathrm{g}$ objectively from the indicated data. So to fix the complementary variability we allow the data $a_{i l}$ in the complementary domain (whose values are unknown anyway) to vary, taking the anticipated values of $c_{i} g_{l}$ : to the extent that the values of $c_{i} g_{l}$ in the complementary domain can be anticipated correctly, the derivatives of the complementary variability 
with respect to $c_{i}$ and $g_{l}$ will be nearly zero, and minimization of the indicated variability can be accomplished. The need to anticipate values of $c_{i}$ and $g_{l}$ before computing them demands an iterative approach. It is convenient to set $a_{i l}=0$ in the complementary domain at the beginning of the iteration. ${ }^{1}$

That the iterative computation just described eventually converges has been observed in practice but not rigorously proven. One of the major advantages of the method, however, is that it could by all appearances be developed within the framework of a powerful formalism known as the E-M (expectation-maximization) algorithm (Little \& Rubin, 1987). For this algorithm, convergence is one of numerous results that have been proven under quite general conditions. The extension of the E-M algorithm to eigenanalysis problems along the lines suggested here would, if successful, yield a potent mathematical technique of wide utility.

Formalization of the computational method is left for future attack, and the theoretical background is here restricted to a demonstration of the appropriate orthogonality condition. It will be proven that least-squares approximations to indicated data yield approximations $\mathrm{cg}$ that are orthogonal to the residual $\mathbf{A}-\mathrm{cg}$ over the indicated domain. This is sufficient to show that all modes in an EOF decomposition obtained by successive applications of the method are likewise orthogonal. The result is useful because if there is no cross-cancellation of the indicated variability between modes, each mode can be said to capture a certain percentage of the total indicated (i.e., observed) variability.

Proof of the orthogonality condition is simple: the indicated residual variability is the variability of $(\mathbf{A}-\mathbf{c g})_{\mathbf{D}}$, the subscript $\mathbf{D}$ meaning that elements not indicated by $\mathrm{D}$ are to be replaced by zeroes, and its derivative with respect to $\mathrm{c}$ is

$$
\frac{\partial}{\partial c} \operatorname{var}(A-c g)_{D}=-2(A-c g){ }_{D} g^{\dagger} .
$$

Since the derivative at a minimum is zero,

$$
\frac{\partial}{\partial c} \operatorname{var}(\mathbf{A}-\mathrm{cg})_{\mathbf{D}}=0
$$

\footnotetext{
${ }^{1}$ Further insight into the workings of the method described in this paragraph can be obtained by working through an analogous problem which is simple enough not to require it: average $x_{1}, x_{2}$, and $x_{3}$ without knowing $x_{3}$. When it is reasonable to proceed by simply ignoring the unknown, the averaging can be done by minimizing $\left(\bar{x}-x_{1}\right)^{2}+\left(\bar{x}-x_{2}\right)^{2}$, leading immediately to $\bar{x}=\left(x_{1}+x_{2}\right) / 2$. But with the same provision it can also be done by setting $x_{3}=0$ initially, minimizing $\left(\bar{x}-x_{1}\right)^{2}+\left(\bar{x}-x_{2}\right)^{2}+\left(\bar{x}-x_{3}\right)^{2}$, and iterating the minimization with $x_{3}$ replaced by the new estimate of $\bar{x}$. The same result is eventually obtained.
} 
and hence

$$
\Sigma_{i l} c_{i} g_{l}\left(a_{i l}-c_{i} g_{l}\right) d_{i l}=\mathrm{c}^{\dagger}(\mathrm{A}-\mathrm{cg})_{\mathrm{D}} \mathrm{g}^{\dagger}=-\frac{1}{2} \mathrm{c}^{\dagger} \frac{\partial}{\partial \mathrm{c}} \operatorname{var}(\mathrm{A}-\mathrm{cg})_{\mathrm{D}}=0,
$$

which is the desired orthogonality condition.

When EOFs are computed by least-squares approximations to indicated data, all data are assigned equal weights (or if desired can be weighted by column or row as described in the text). A modification of this technique, for certain cases which can be treated analytically, yielded the optimal decomposition of the example presented earlier (eq. 8), with $\operatorname{var}_{\mathbf{D}}\left(\dot{\mathbf{A}}-\mathbf{A}^{\prime}{ }_{1}\right)=6.66$. 


\section{Part 2. Occurrence of extreme sea levels}

\section{Data coverage}

The raw sea-level data for the sea-level extremes study consist of hourly tidal heights measured at 5 tide-gauge stations on the eastern coast of the United States (table 6 and fig. 9), and obtained on magnetic tape from the National Ocean Service (NOS), together with harmonic constants for each station. Storm data are monthly counts tabulated by Dolan et al. (1987).

\begin{tabular}{r|l|rr}
\multicolumn{2}{l}{} & \multicolumn{2}{c}{ Data coverage* } \\
No. & Station name & $1910-1989$ & \\
\hline 1 & PORTLAND ME & $1920-1989$ & $1948-1984$ \\
2 & THE BATTERY NY & $1911-1985$ & $1948-1984$ \\
3 & ATLANTIC CITY NJ & $1927-1988$ & \\
4 & HAMPTON RDS VA & $1897-1988$ & \\
5 & FERNANDINA BEACH FL & 1897 & \\
\hline
\end{tabular}

* Key to data coverage: (a) data received

(b) data used in compiling monthly exceedance counts

Table 6: Data coverage for study of sea-level extremes.

All of the hourly sea-level series contain numerous small gaps. There is also a 5-year gap in sea-level coverage at Atlantic City, from 1950 through 1954. The appearance of the raw data is illustrated by fig. 10 .

Data quality assessment for the five sea-level stations will eventually require visual inspection of the entire record from each one, plus comparison of monthly means with the "Revised Local Reference" data avaliable from the Permanent Service for Mean Sea Level. This process remains incomplete, but the two stations for which exceedance-count tables have been compiled have been checked sufficiently to ensure their reliability in a study of annual cyclicity. Data received for the non-existant date 31 November 1965 in the New York series have been ignored. A search for outliers found that all data in the two 1948-1984 series lie within the range of variability associated with storm surges. Genuine storm surges are usually recognizable by their appearance in more than one series, and by their shape. Some sections of the Atlantic City record, however, were found to include 


\section{LOCATIONS OF SEA-LEVEL STATIONS $\bullet=\mathrm{RLR}$}

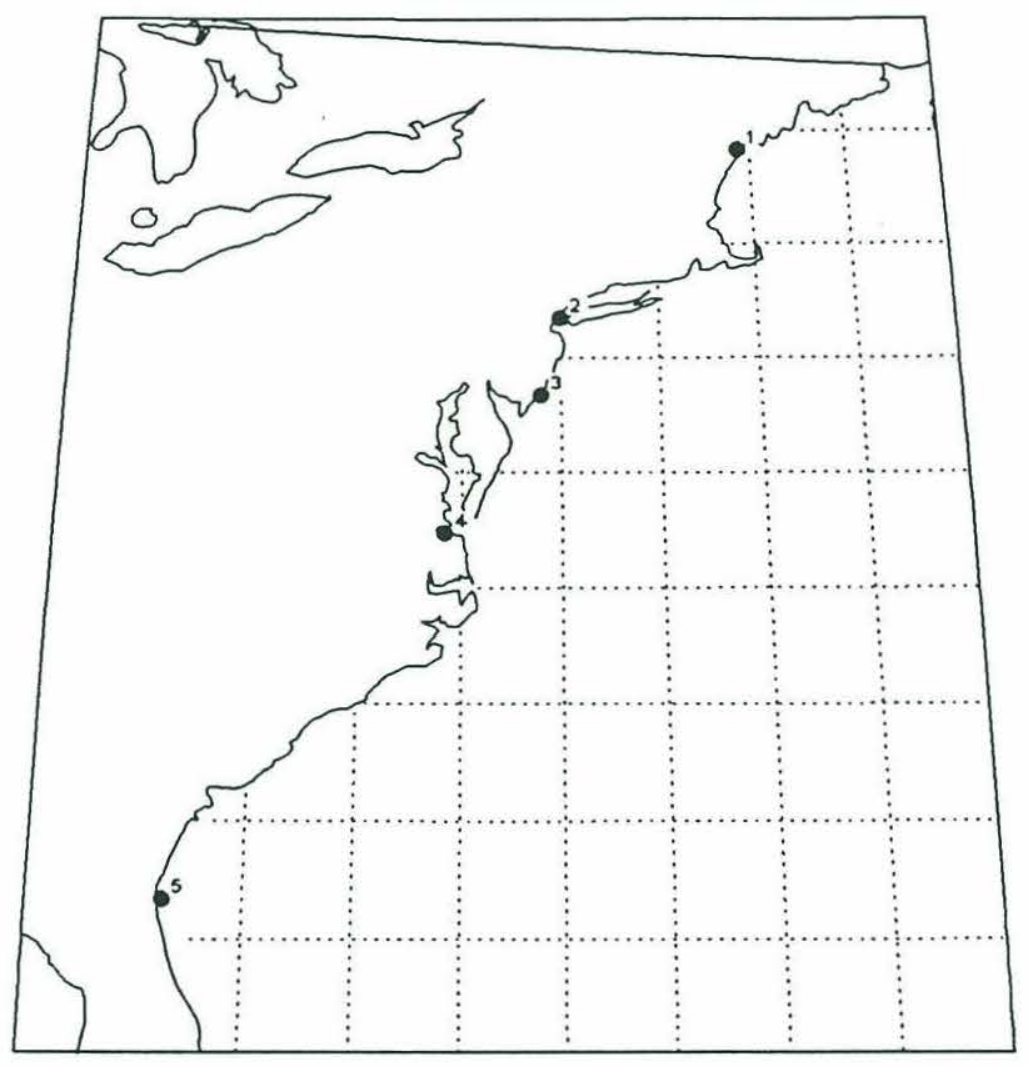

Figure 9: Locations of 5 sea-level stations on the U.S. East Coast. 

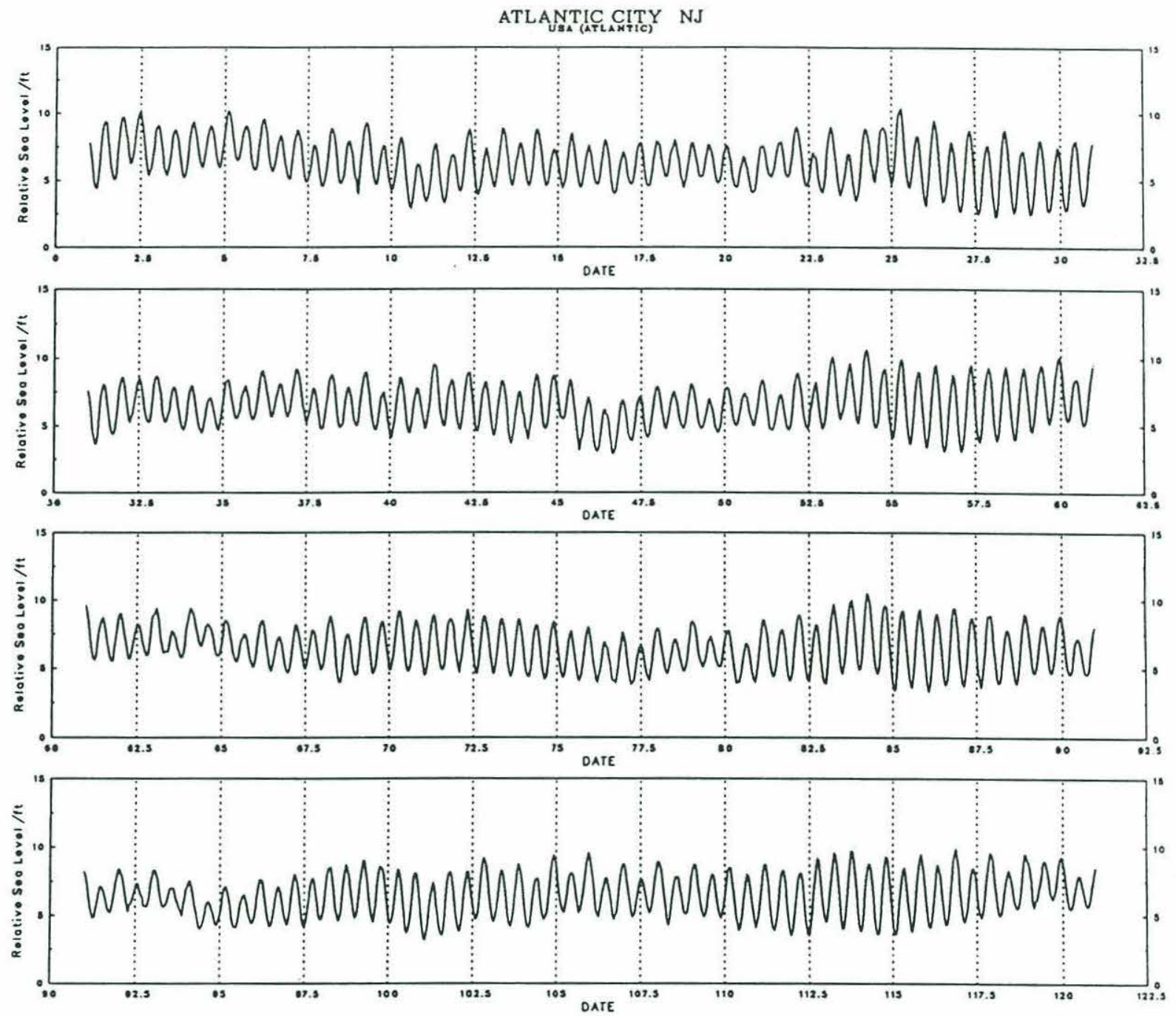

Figure 10: Approximately four months of hourly tide-gauge data from Atlantic City. Days are numbered consecutively beginning January 1, 1948. 


\begin{tabular}{|c|c|c|c|c|c|}
\hline Station Name & Year(s) & Month(s) & Date(s) & Hour(s) & Reason for removal \\
\hline \multirow[t]{5}{*}{ ATLANTIC CITY } & \multirow[t]{3}{*}{1973} & \multirow[t]{3}{*}{ May } & $9-10$ & $0-23$ & $\begin{array}{l}\text { Mean level is at least } 3 \\
\text { feet higher than usual }\end{array}$ \\
\hline & & & $\begin{array}{l}12 \\
13\end{array}$ & $\begin{array}{c}20-23 \\
0\end{array}$ & $\begin{array}{l}\text { Low values showing no tidal } \\
\text { variation }\end{array}$ \\
\hline & & & $\begin{array}{l}13 \\
14\end{array}$ & $\begin{array}{c}20-23 \\
0-1\end{array}$ & $\begin{array}{l}\text { Low values showing no tidal } \\
\text { variation }\end{array}$ \\
\hline & \multirow[t]{2}{*}{1978} & \multirow{2}{*}{ August } & \multirow[t]{2}{*}{21} & $0-11$ & Rapidly changing values \\
\hline & & & & $12-20$ & $\begin{array}{l}\text { Low values showing no tidal } \\
\text { variation }\end{array}$ \\
\hline
\end{tabular}

Table 7: Data removed from series prior to analysis.

fluctuations comparable in magnitude to storm surges, but which neither resemble surges in appearance nor correlate with events in other series. They were removed and are listed in table 7 .

\section{Compilation of monthly exceedance counts}

With the broader aims of the extreme sea-level study in mind, a FORTRAN subprogram named RSLNOS has been written to:

- read and interpret hourly-height data received from NOS,

- summarize the availability of data,

- save the data in unformatted files which can also be read as input,

- compute the tidal component of the hourly heights from a list of harmonic constants,

- call a data-processing subroutine that may be added at 'link' time, and/or

- plot the data in a manner that can be altered at 'run' time.

The tidal prediction package used to compute the tidal component of the data can be included or omitted at 'compile' time since it roughly triples the usage of memory. It emulates the tidal prediction program written by M.G.G. Foreman (1977) and incorporates some of Foreman's subroutines without modification; auxiliary plotting software is included so that (for example) tidal and residual curves can be plotted together. The input to the 
tidal prediction package consists of Foreman's standard tidal-constituent data listing, plus a list of tidal constituents with known amplitude and phase lag specified for each station. Hour values in the present implementation are local, not Greenwich, times, so the modified phase lag (identified as $\kappa^{\prime}$ in the tables of harmonic constants received from NOS) is used.

Hourly 'surge' levels are derived by subtracting predicted tidal heights from observed heights. Fig. 11 compares a 'surge' record with the corresponding tidal predictions; by summing the two curves shown, the actual sea-level observations can be recovered. Fig. 11 illustrates the typical appearance of the 'surge' record during relatively quiet intervals, as well as one of the highest surge events occurring during the interval studied. Even under calm conditions the 'surge' record tends to fluctuate within a range of about 2 feet over the course of a day, and numerous 'surge'-level maxima occur in most 24-hour periods.

It does not seem desirable that fluctuations on the scale of a few hours or less should be counted as separate events in this study, since the weather disturbances that give rise to extreme surges are likely to persist for a day or so - as may be seen in fig. 11. It would be possible to filter out the higher frequencies present, but in lieu of such smoothing an algorithm has been utilized which guarantees no two extreme events can be recognized unless they are separated by at least one calendar day with no maximum higher than either event. The algorithm first eliminates all but the highest maximum on each calendar day. It then counts the maximum as an extreme event only if no higher maximum occurred on either the preceding day or the following day.

To ensure that exceedance counts were unaffected by missing observations, they were computed only if all hourly observations for the month, and for the preceding day and the following day, were available. This criterion was met by 379 months in the New York series and 308 months in the Atlantic City series (out of 444 possible). Extreme events during those months were identified according to the algorithm just described, and the number of extreme events exceeding a chosen threshold value-the exceedance count-was obtained for each month. For ease of comparison with the published storm counts (Dolan et al., 1987), various threshold values were selected until trial and error yielded an average monthly exceedance count close to the average monthly storm count (about 2.7) in the published data.

Monthly exceedance counts based on the 'surge'-level records were compiled, as well as counts based on the original sea-level data. Threshold values chosen for both the sea-level and 'surge'-level exceedance counts are given in table 8 , along with the average number of exceedances per month. The previously published storm counts are also exceedances of 


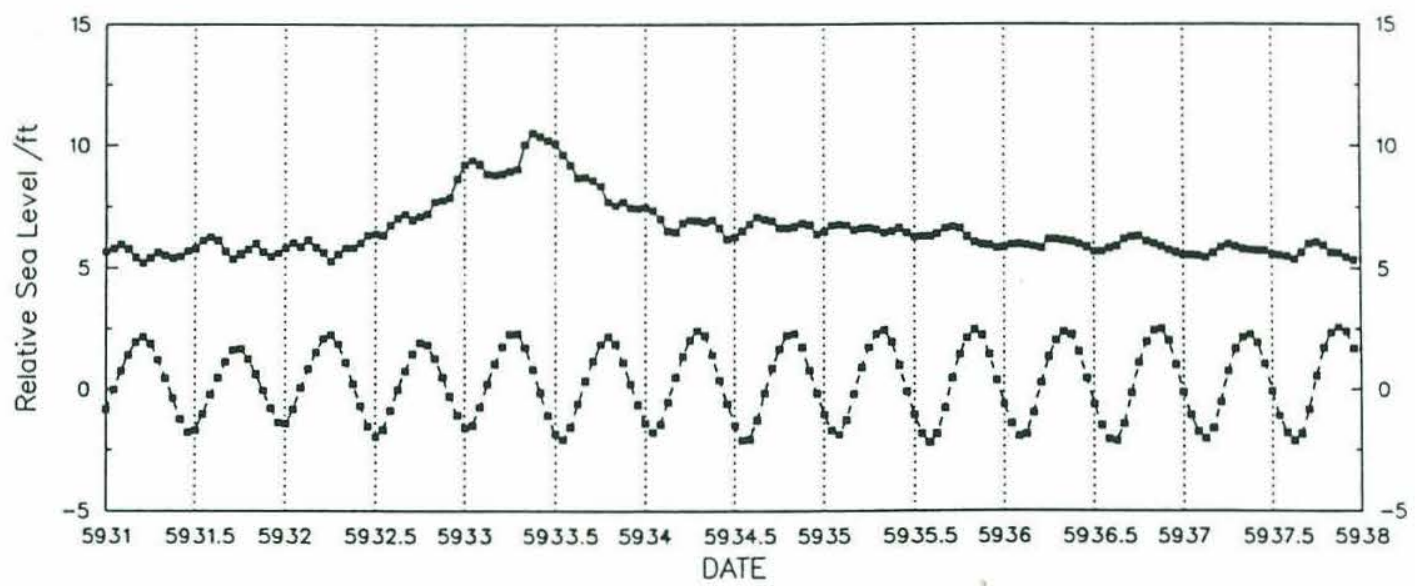

Figure 11: Tide and 'surge' components of a tide-gauge record. The lower curve is the computed tidal component and the upper curve is the observed height with the tidal component removed 


\begin{tabular}{|r|l|cc|cc|}
\multicolumn{2}{c}{} & \multicolumn{3}{c}{ Sea levels* $^{*}$} & \multicolumn{2}{c}{ Surge levels* } \\
No. & Station name & \multicolumn{1}{c}{ T } & CNT & T & CNT \\
\hline 2 & THE BATTERY NY & 8.8 & 2.34 & 6.6 & 2.44 \\
3 & ATLANTIC CITY NJ & 9.9 & 2.41 & 7.8 & 2.35 \\
\hline
\end{tabular}

* Key: $\mathrm{T}=$ threshold in feet

$\mathrm{CNT}=$ average monthly exceedance count

Table 8: Thresholds and average exceedance counts.

a threshold value - specifically, a wave height of 5 feet $(1.6 \mathrm{~m})$. They can be regarded as 'wave-level' exceedances, where 'wave level' is the significant wave height, hindcasted from estimated fetch length and wind speed.

\section{Comparison of exceedance counts and storm counts}

Until more detailed data quality evaluation is carried out (such evaluation being among the next steps in the project), it is not certain that heights (and therefore exceedance counts) are directly comparable over long intervals. Consequently certain patterns in the data cannot be interpreted safely at this time, including an obvious increase in 'surge'level exceedance counts around 1970. Also falling in this category is the joint distribution of storm counts and exceedance counts, which there is little point in quantifying at this stage. It may be noted, however, that with the data in their present form, the r.m.s. (root mean square) difference between storm counts and 'surge'-level exceedance counts is 2.5 at both stations, nearly equal to the mean storm count or exceedance count. Thus, a full interpretation of the relationship between the two measures will have to account for considerable differences between them.

A more specific feature appropriate for analysis at the present stage is the annual cycle of variability which, being repetitive, is readily studied by averaging the storm counts or exceedance counts for each month over the years of record available. This largely removes from consideration the problems associated with the definition and control of a reference level over several decades.

The 'surge'-level exceedance data (table 9) at both stations show a minimum frequency of occurrence in May and a maximum in November or December. The ratios of extreme 


\begin{tabular}{|c|c|c|c|c|}
\hline & \multicolumn{2}{|c|}{ ATLANTIC CITY } & \multicolumn{2}{|c|}{ THE BATTERY } \\
\hline & Sea level & 'Surge' level & Sea level & 'Surge' level \\
\hline & CNT & CNT & $\mathrm{CNT}$ & CNT \\
\hline JAN & 2.71 & 4.25 & 2.13 & 3.80 \\
\hline FEB & 2.28 & 3.44 & 2.10 & 2.90 \\
\hline MAR & 2.21 & 2.21 & 2.44 & 2.66 \\
\hline APR & 1.74 & 0.91 & 2.19 & 1.50 \\
\hline MAY & 1.61 & 0.65 & 2.25 & 0.38 \\
\hline JUN & 2.00 & 1.17 & 2.12 & 0.74 \\
\hline JUL & 1.61 & 1.21 & 1.48 & 0.45 \\
\hline AUG & 2.25 & 1.25 & 1.84 & 1.38 \\
\hline SEP & 2.90 & 1.97 & 2.28 & 2.78 \\
\hline OCT & 3.43 & 2.86 & 3.28 & 4.12 \\
\hline NOV & 3.07 & 3.52 & 3.23 & 4.55 \\
\hline DEC & 2.80 & 4.68 & 2.80 & 4.30 \\
\hline $\max : \min$ & $2.1: 1$ & $7.2: 1$ & $2.2: 1$ & $12.0: 1$ \\
\hline
\end{tabular}

Table 9: The annual cycle of monthly exceedance counts: an average over 40 years, subject to data availability.

frequencies show that exceedances at the time of maximum frequency are more likely by an order of magnitude than during the May minimum. Dolan et al.'s storm-count data, when averaged over the same interval, show a similar maximum/minimum ratio $(7.3: 1)$ but peak in February and reach a minimum in July.

A plot of the storm-count and 'surge'-level exceedance-count data (fig. 12) in fact shows that during eight months of the year (November-June) both sets of data exhibit nearly sinusoidal variation, with the exceedance counts leading the storm counts by almost two months. This impression is confirmed by a least-squares fit of sinusoids to the three curves over all 12 months, which reveals a phase lead of 1.42 months at Atlantic City and 1.75 months at New York.

The phase leads stated here are intended as descriptive quantities which need not indicate a cause-and-effect relationship between the two variables. In fact, a sinusoidal 


\section{AVERAGED MONTHLY COUNTS SURGE-LEVEL EXCEEDANCES STORMS}

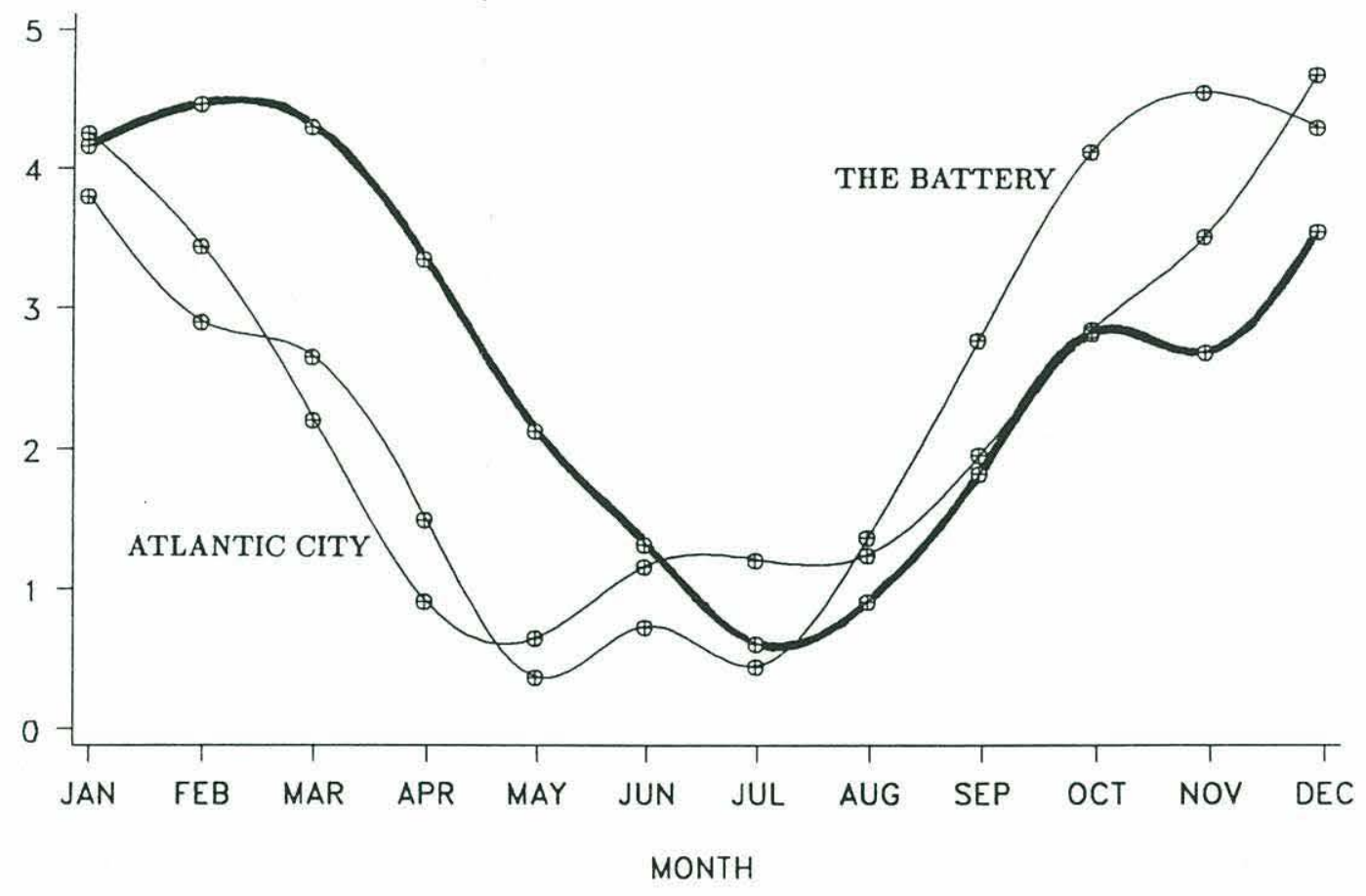

Figure 12: The annual cycle of monthly 'surge'-level exceedance counts (data from table 9) compared with monthly storm counts of Dolan et al. (1987) averaged over the same interval. 
variation may not be the most suitable model for the frequency of both storms and 'surge'level exceedances in the first place. The sinusoidal model certainly accounts for most of the variability (more than $90 \%$ in all cases) and the phase leads could reflect geographical variations, but otherwise the explanation for the observed phase lead may have to be sought on a month-by-month or season-by-season basis. Differences in wind direction associated with storms at different times of the year, for instance, could be important.

There is at least one hypothesis that could explain apparent differences between the annual cycles of storm and 'surge' occurrence as an artifact of the analysis method employed. This is that part of the 'surge' record has inadvertently been removed along with the solar annual (Sa) tidal constituent. In fact it is inevitable that the least-squares harmonic analysis used to estimate the harmonic constants of the tidal constituents will capture any sea-level variability at a period of one year without distinguishing the astronomical from the meteorological or oceanographic contributions. In the prediction of sea levels without consideration of stochastic events like storms, it is appropriate to treat any periodically occurring variations as if they were tides; but when meteorological or oceanographic contributions are accounted for in a model, those at tidal frequencies should ideally be modelled in the same manner as those at other frequencies, the spectrum of non-tidal fluctuations being a continuous one. Adherance to this principle requires that the fitting of the model involve only "non-tidal" frequencies-i.e., those at which astronomical contributions to the sea-level variance can be presumed negligible. At tidal frequencies, the model is required as input so that tidal and non-tidal contributions can be separated instead of attributing all variance to one source or the other.

When comparing the magnitude of storm 'surges' at different times of the year, the nature of the Sa tidal constituent is an issue to be kept in mind. The implications with regard to the phase leads reported above were investigated by constructing a second exceedancecount data set based on 'surge' records from which the solar annual tide had not been removed. The annual oscillation of the 'surge'-level exceedance frequency was found to be less pronounced or, in the case of Atlantic City, barely significant, but the change in the phase estimates was less than a month at both Atlantic City and New York City. The phase leads, therefore, cannot be dismissed as artifacts of the tide-removal process unless the predicted (fitted) Sa constituent is believed to be nearly in antiphase with the true one.

Recall that observed sea level is the sum of 'surge' level and the predicted tide. The timing of sea-level exceedances therefore depends on tidal phase as well as on the 'surge' 
conditions discussed above. As might be expected, the sea-level exceedance data do not reflect the annual cycle of meteorological variability as clearly as the 'surge'-level data do. The rise to a maximum frequency, in October at both stations, is evident, but no pronounced minimum appears. The relative flatness of the sea-level exceedance cycle during this time, when the 'surge'-level exceedance frequency dips to a minimum, may mean that extreme tides alone (e.g., perigean spring tides) are as important as extreme 'surges' during these quieter summer months.

Much of the information needed to test this hypothesis is included in the data set under examination, but investigation has shown that the algorithm used to compile exceedance counts - which was designed primarily to study surge-level exceedances-is not well suited to the study of predicted tide levels or observed sea levels, which both exhibit strong diurnal periodicity at the stations in question. For this reason, further study of actual sealevel extremes, and especially of the importance of tides during summer months, should be based on exceedance counts derived by a different algorithm. The new algorithm should divide the record into sub-record intervals centered near predicted tidal maxima, which at the stations under consideration occur almost at the frequency of the dominant (M2) tidal constituent. The relative importance of tides and surges to the occurrence of extreme sea levels is a quantifiable variable, undoubtedly subject to geographical and temporal variations, which could be helpful to coastal engineers. Its measurement might be worth including among the next goals of this investigation.

Once questions of data consistency over the long term have been settled (see p. 53), it will be possible to examine the distribution of individual monthly exceedance counts about the mean values in table 9 and fig. 12. In particular, it will be possible to test whether the values have the expected Poisson distribution, and whether their mean is subject to secular variation. Statistical tests of this type are described by Snedecor and Cochran (1980, §§7.14, 11.4, 11.5).

\section{Conclusions}

1. Considerable differences exist between the number of storms and the number of 'surge'-level exceedances occurring during any month, and are associated in part with differences between the annual cycles of storm frequency and 'surge'-level exceedance frequency. If the cycles are modelled as strictly sinusoidal variations over the course of the year, 'surge'-level exceedance frequency is found to lead storm frequency by 
about $1 \frac{1}{2}$ months at both Atlantic City and New York City.

2. The estimated magnitude of the annual tide, which may include meteorological and oceanographic effects, is large enough to affect exceedance counts noticeably, depending on whether it is counted as part of the 'surge' or the astronomical tide. Attributing it to 'surge' reduces the amplitude, but does not much alter the phase, of the annual 'surge'-level exceedance cycle.

3. During the relatively storm-free months of the mid-Atlantic summer, actual sealevel exceedance counts do not drop off as sharply as 'surge'-level exceedance counts do, suggesting that stochastic events are no more important than predictable tidal fluctuations in causing extreme sea levels at this time of year. The relative importance of tide and surge contributions to sea-level exceedances at different times of the year should be investigated further after modifying the algorithm used to count exceedances. 


\section{References}

[1] Aubrey, D.G. (1985). Recent sea levels from tide gauges: problems and prognosis. In: National Research Council, Glaciers, Ice Sheets, and Sea Level: effect of a $\mathrm{CO}_{2}$-induced climatic change. Washington: Nat'l Academy Press; U.S. Dept. of Energy, pp. 73-91.

[2] Aubrey, D.G. and Emery, K.O. (1986). Relative sea levels of Japan from tidegauge records. Geological Society of America Bull. 97:194-205; 1281 (discussion by R. Ehrlich and I. Lerche); 1282 (reply by D.G. Aubrey and K.O. Emery).

[3] Barnett, T.P. (1983). Recent changes in sea level and their possible causes. Climatic Change 5: 15-38.

[4] Barnett, T.P. (1984). The estimation of "global" sea level change: a problem of uniqueness. J. of Geophysical Research 89(C5):7980-7988.

[5] Broadus, J., Milliman, J., Edwards, S., Aubrey, D., and Gable, F. (1986) Rising sea level and damming of rivers: possible effects in Egypt and Bangladesh. In: Titus, J.G. (ed.), Effects of Changes in Stratospheric Ozone and Global Climate, vol. 4: Sea Level Rise. Washington: U.S. Environmental Protection Agency, pp. 165-189.

[6] Carter, W.E., Robertson, D.S., and McKay, J.R. (1985). Geodetic radio interferometric surveying: applications and results. J. of Geophysical Research 90:45774587.

[7] Charlesworth, J.K. (1957). The Quaternary Era, in 2 vols. London: Arnold, p. 1328. Cited by: VITA-FinZI, C. (1986). Recent Earth Movements: an introduction to neotectonics. London: Academic, p. 198.

[8] Dolan, R., Hayden, B., Bosserman, K., and Lisle, L. (1987). Frequency and magnitude data on coastal storms. J. of Coastal Research 3:245-247.

[9] Donovan, D.T. and Jones, E.J.W. (1979). Causes of world-wide changes in sea level. J. of the Geological Society of London 136:187-192.

[10] Draper, N.R. and Smith, H. (1981). Applied Regression Analysis, 2nd edn. New York: John Wiley \& Sons, 709 p.

[11] Emery, K.O. (1980). Relative sea-levels from tide-gauge records. Proc. of the Nat'l Academy of Sciences of the U.S.A. 77:6968-1972.

[12] Etkins, R. and Epstein, E.S. (1982). The rise of global mean sea level as an indication of climatic change. Science 215: 287-289.

[13] Fairbridge, R.W. (1961). Eustatic changes in sea level. Physics and Chemistry of the Earth 4:99-185.

[14] Fairbridge, R.W. and Krebs, O.A., Jr. (1962). Sea level and the Southern Oscillation. Geophysical J. of the Royal Astronomical Society 46:647-667.

[15] Foreman, M.G.G. (1977). Manual for Tidal Heights Analysis and Prediction (Pacific Marine Science Report 77-10). Victoria (B.C.): Institute of Ocean Sciences, 101 p. 
[16] Gornitz, V. and LebedefF, S. (1987). Global sea-level changes during the past century. In: Nummedal, D., Pilkey, O.H., and Howard, J.D. (eds.), Sea-Level Fluctuation and Coastal Evolution (Society of Economic Paleontologists \& Mineralogists Special Publ. 41). Tulsa (Okla.): SEPM, pp. 3-16.

[17] Gornitz, V., Lebedeff, S., and Hansen, J. (1982). Global sea level trend in the past century. Science 215(4540): 1611-1614.

[18] Gutenberg, S. (1941). Changes in sea level, postglacial uplift, and mobility of the earth's interior. Bull. of the Geological Society of America 52:721-772.

[19] Hoffman, J.S. (1984). Estimates of future sea level rise. In: Barth, M.C. and Titus, J.G. (eds.), Greenhouse Effect and Sea Level Rise: a challenge for this generation. New York: Van Nostrand Reinhold, pp. 79-103.

[20] IApso (International Association for the Physical Sciences of the Ocean), Advisory Committee on Tides and Mean Sea level (1985). Changes in relative mean sea level. EOS (Trans. of the American Geophysical Union) 66(45): 754-756.

[21] Jones, P. (1984). Multivariate analysis: classical methods. In: Lloyd, E. (ed.), Handbook of Applicable Mathematics, vol. 6: Statistics, Part B. Chichester: John Wiley \& Sons, pp. 689-725.

[22] Kalinin, G.P. and Klige, R.K. (1978). Variation in the world sea level. In: World Water Balance and Water Resources of the Earth (Unesco Studies and Reports in Hydrology, 25), pp. 581-585. Cited by Pirazzoli (1986).

[23] Kaula, W.M. (1980). Problems in understanding vertical movements and earth rheology. In: MörNER, N.-A. (ed.), Earth Rheology, Isostasy and Eustasy (Geodynamics Project Scientific Report 49). Chichester: John Wiley \& Sons, pp. 577-588.

[24] KLIGE, R.K. (1982). Oceanic level fluctuations in the history of the earth. In: Sea and Oceanic Level Fluctuations for 15,000 Years. Acad. Sci. USSR, Inst. of Geog., Moscow, Nauka (in Russian). Cited by RoBIN (1986).

[25] Lamb, H.H. (1982). Climate, History, and the Modern World. London: Methuen, 387 p. (see pp. $107,155,176,267$.)

[26] Lisitzin, E. (1958). Le niveau moyen de la mer. Comité Central d'Océanographie et d'Étude des Côtes Bull. d'Information 10:254-262.

[27] Lisitzin, E. (1974). Sea Level Changes (Elsevier Oceanography Series, 8). New York: Elsevier, $286 \mathrm{p}$.

[28] Little, R.J.A. and Rubin, D.B. (1987). Statistical Analysis with Missing Data. New York: John Wiley \& Sons, 278 p.

[29] Lorenz, E.N. (1956). Empirical Orthogonal Functions and Statistical Weather Prediction (Massachusetts Institute of Technology Dept. of Meteorology, Statistical Forecasting Project Scientific Report 1). [Cambridge (Mass.): M.I.T.] 49 p.

[30] Mercer, J.H. (1978). West Antarctic ice sheet and $\mathrm{CO}_{2}$ greenhouse effect: a threat of disaster. Nature 271:321-325.

[31] Mörner, N.-A. (1976). Eustasy and geoid changes. J. of Geology 84:123-151. 
[32] Mörner, N.-A. (1986). The concept of eustasy: a redefinition. In: Pirazzoli, P.A. and Suter, J.R. (eds.), Late Quaternary Sea-Level Changes \& Coastal Evolution (J. of Coastal Research Special Issue 1). Fort Lauderdale (Fla.): Coastal Education and Research Foundation, pp. 49-51.

[33] Mosby, H. (1957). Cited by Fairbridge (1961), as follows in full: "At the I.U.G.G. meeting in Toronto (1957), HAKoN MosBY announced that a revision of the mean world rate of rise is now available, rising to $2.25 \mathrm{~cm}$ for the last 20 years, that is an average of $1.12 \mathrm{~mm}$ per year."

[34] Nikonov, A.A. (1980). Manifestations of glacio-isostatic processes in northern countries during the Holocene and at present. In: Mörner, N.-A. (ed.), Earth Rheology, Isostasy and Eustasy (Geodynamics Project Scientific Report 49). Chichester: John Wiley \& Sons, pp. 341-354.

[35] Pirazzoli, P.A. (1986). Secular trends of relative sea level (RSL) changes indicated by tide-gauge records. In: Pirazzoli, P.A. and Suter, J.R. (eds.), Late Quaternary Sea-Level Changes 85 Coastal Evolution ( J. of Coastal Research Special Issue 1). Fort Lauderdale (Fla.): Coastal Education and Research Foundation, pp. 1-26.

[36] Pitman, W.C., III (1978). Relationship between eustacy and stratigraphic sequences of passive margins. Geological Society of America Bull. 89(9): 1389-1403.

[37] Robin, G. DE Q. (1986). Changing the sea level: projecting the rise in sea level caused by warming of the atmosphere. In: BoLIN, B., Döös, B.R., JÄGER, J., and Warrick, R.A. (eds.), The Greenhouse Effect, Climatic Change, and Ecosystems (SCOPE 29). Chichester: John Wiley \& Sons, pp. 323-359.

[38] Smith, R.A. (1980). Golden Gate tidal measurements: 1854-1978. J. of the Waterway Port Coastal and Ocean Division (Proc. of the American Society of Civil Engineers) 106: 407-410.

[39] Snedecor, G.W. and Cochran, W.G. (1980). Statistical Methods, 7th edn. Ames (Iowa): Iowa State Univ. Press, 507 p.

[40] Suess, E. (1904/24). The Face of the Earth, in 5 vols., trans. by Sollas. Oxford. Cited by Fairbridge (1961).

[41] Thomas, R. (1986). Future sea level rise and its early detection by satellite remote sensing. In: Titus, J.G. (ed.), Effects of Changes in Stratospheric Ozone and Global Climate, vol. 4: Sea Level Rise. Washington: U.S. Environmental Protection Agency, pp. 19-36. 